University of New Hampshire

University of New Hampshire Scholars' Repository

Master's Theses and Capstones

Student Scholarship

Spring 2009

\title{
Validity and reliability of the Critical Care Pain Observation Tool: A replication study
}

Kathleen Marie Keane

University of New Hampshire, Durham

Follow this and additional works at: https://scholars.unh.edu/thesis

\section{Recommended Citation}

Keane, Kathleen Marie, "Validity and reliability of the Critical Care Pain Observation Tool: A replication study" (2009). Master's Theses and Capstones. 449.

https://scholars.unh.edu/thesis/449

This Thesis is brought to you for free and open access by the Student Scholarship at University of New Hampshire Scholars' Repository. It has been accepted for inclusion in Master's Theses and Capstones by an authorized administrator of University of New Hampshire Scholars' Repository. For more information, please contact Scholarly.Communication@unh.edu. 


\section{NOTE TO USERS}

\section{Page(s) not included in the original manuscript are unavailable from the author or university. The manuscript was microfilmed as received}

\section{3-40}

This reproduction is the best copy available.

\section{UMI}




\title{
VALIDITY AND RELIABILITY OF THE CRITICAL CARE PAIN OBSERVATION
}

TOOL: A REPLICATION STUDY

\author{
BY \\ KATHLEEN MARIE KEANE \\ Bachelor of Science, Columbia University, 1989
}

\section{THESIS}

Submitted to the University of New Hampshire

In Partial Fulfillment of

the Requirements for the Degree of

\author{
Master of Science \\ in
}

Nursing

May 2009 
UMI Number: 1466937

\section{INFORMATION TO USERS}

The quality of this reproduction is dependent upon the quality of the copy submitted. Broken or indistinct print, colored or poor quality illustrations and photographs, print bleed-through, substandard margins, and improper alignment can adversely affect reproduction.

In the unlikely event that the author did not send a complete manuscript and there are missing pages, these will be noted. Also, if unauthorized copyright material had to be removed, a note will indicate the deletion.

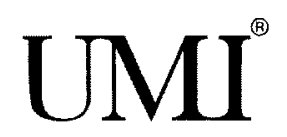

UMI Microform 1466937

Copyright 2009 by ProQuest LLC

All rights reserved. This microform edition is protected against unauthorized copying under Title 17, United States Code.

ProQuest LLC

789 East Eisenhower Parkway

P.O. Box 1346

Ann Arbor, MI 48106-1346 
This thesis has been examined and approved.

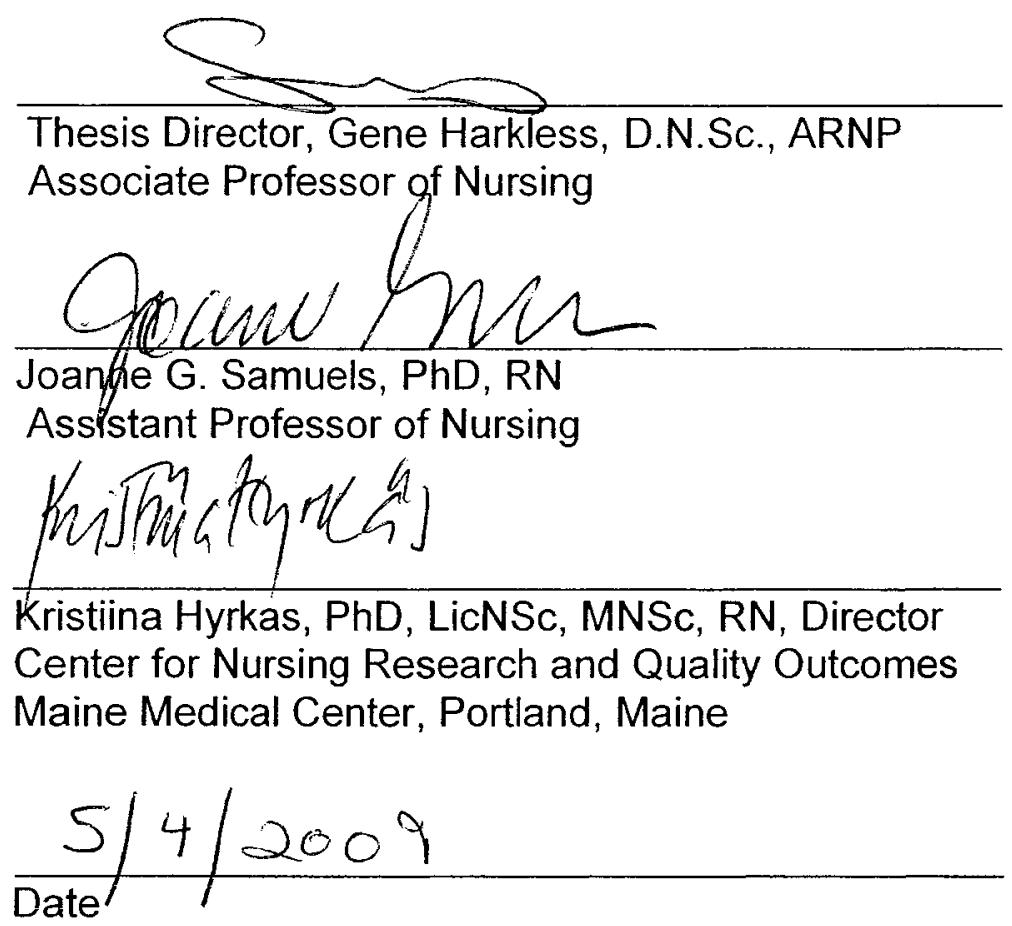




\section{DEDICATION}

To my parents, Maria and Thomas.

With gratitude and love. 


\section{ACKNOWLEDGEMENTS}

Embarking on my graduate study and the joy of scholarly learning would not have been possible with the unflagging support of my husband, Stephen Small. I will always be grateful for his selfless gifts of love, for his listening and his thoughtful reflection.

I want to thank my children, Moses and Christopher for giving Mom her study time and for celebrating my successes with me. You both are a joy to me and a constant source of inspiration.

My scholarly journey began through a meeting with my cherished mentor Dr Alyce Schultz. Dr Schultz changed my life by reigniting my passion to learn, to question and celebrate the process with fellow nurses. I will be forever grateful to have shared the experience of a culture of learning, inclusiveness and generosity of spirit.

My graduate study was supported by gifted and passionate teachers who each brought their unique talents to teaching and to their classes. My work was inspired by each and every one and I want to thank them for their contribution to my growth. They include Dr. Raelene Shippee Rice, Dr. Lynette A. Hamlin, Dr. Pamela DiNapoli, and Dr. Susan Fetzer. Thank you to my clinical mentor, Margaret Higgins and the staff of 7AB at Brigham and Women's Hospital for a wonderful clinical experience. Their work is affirmation of the healing power of nurses. 
Thank you to Dr Gene Harkless, the chairperson of my thesis committee. Her guidance and mentorship have enriched my education immeasurably. Dr Harkless has inspired me to be the best that I can be and I seek to emulate her in my continued work. I am truly honored to have worked with her and her colleague, Dr. Joanne Samuels.

Thank you to the staff of the Cardiothoracic Intensive Care Unit at Maine Medical Center, to my professional colleagues and to nursing director Cheryll St Onge. The challenges of undertaking research in the clinical setting were overcome with the support and guidance of my work community. Thank you to Dr. Kristiina Hyrkas, a reader of the thesis, for her insightful comments on manuscript as well as suggestions guiding the process of this project.

Thank you to Tania Strout, a role model, mentor and friend whose expertise was invaluable in discussing the challenges inherent in the study of pain assessment as well as in guiding me in performing statistical analyses.

I will always be grateful to the community of family, friends, colleagues and teachers who have nurtured me and my work. 


\section{TABLE OF CONTENTS}

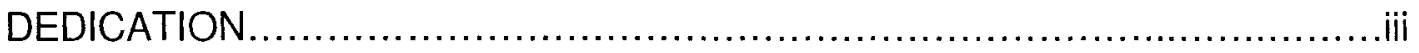

ACKNOWLEDGEMENTS.............................................................

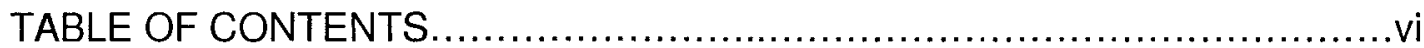

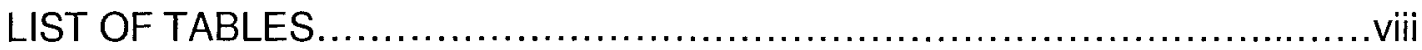

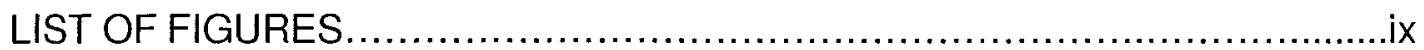

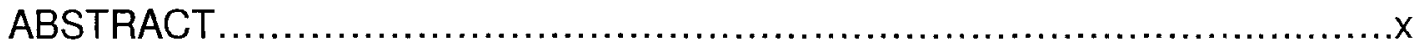

CHAPTER PAGE

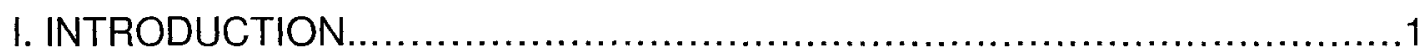

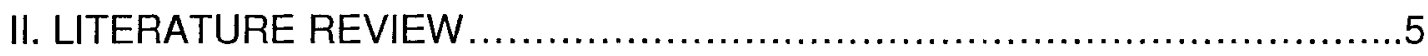

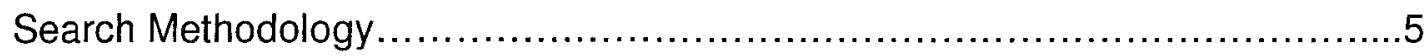

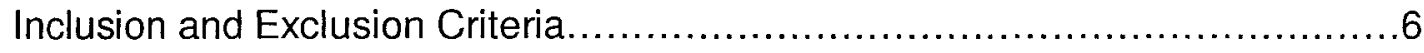

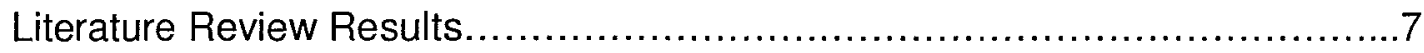

Conceptual Framework .......................................................13

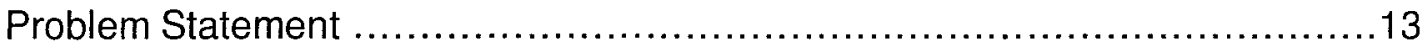

Research Question............................................................

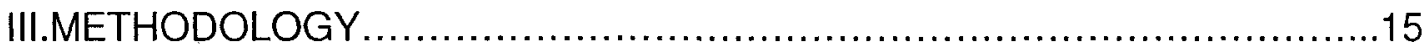

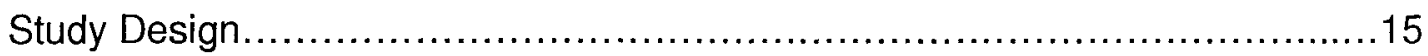

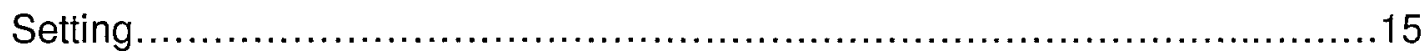

Patient Sample and Population...............................................16






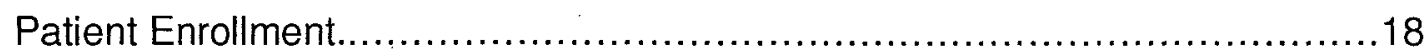

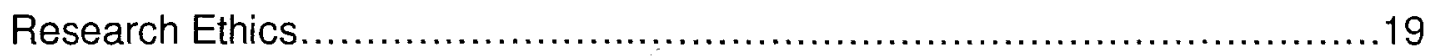

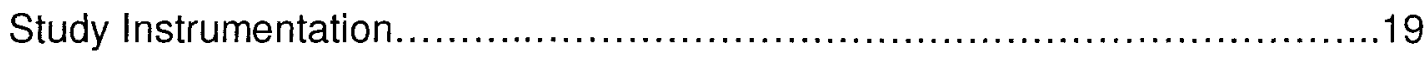

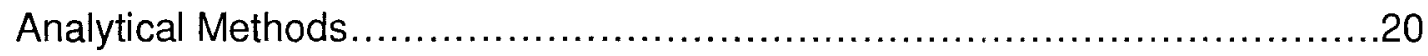

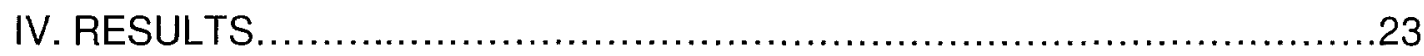

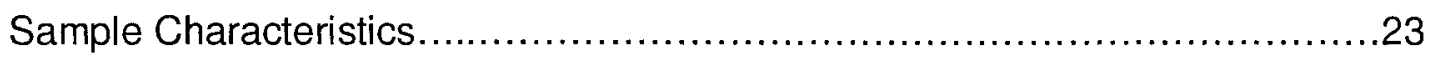

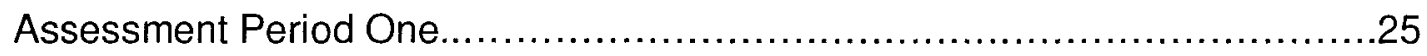

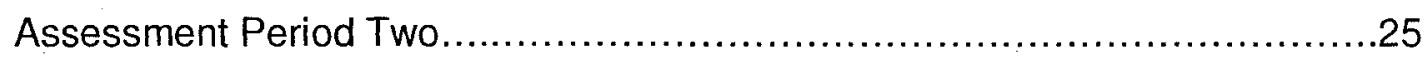

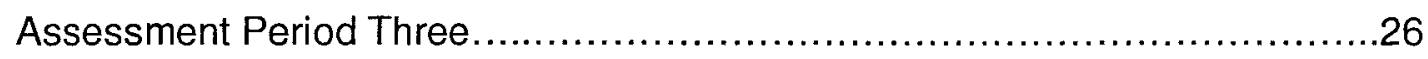

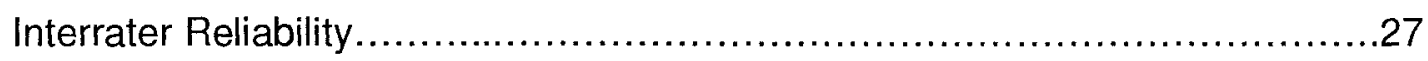

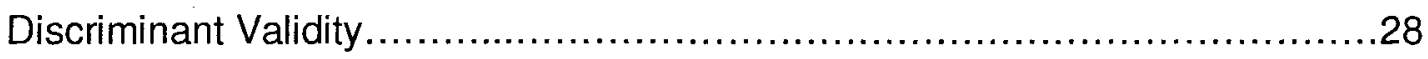

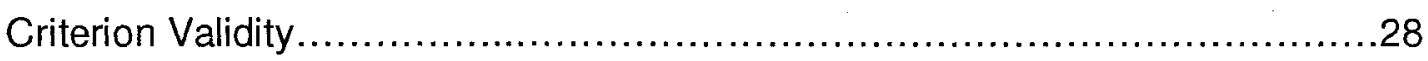

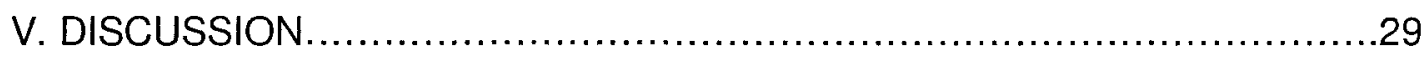

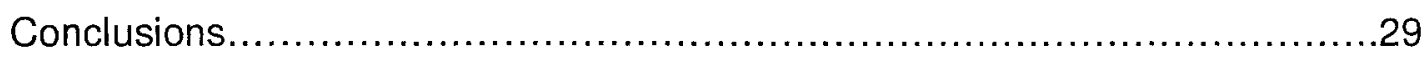

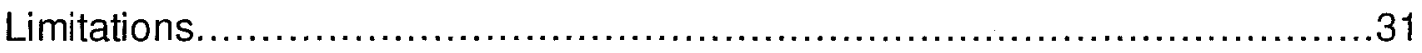

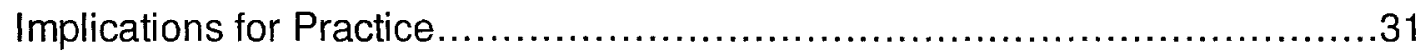

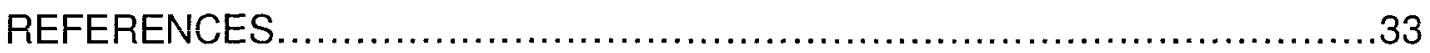

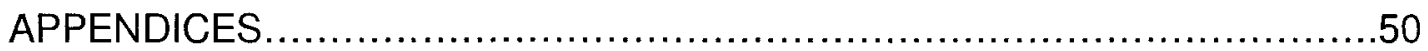

APPENDIX A Literature Review Summary Table...................................51

APPENDIX B Comparison of Pain Assessment Instruments......................61

APPENDIX C Institutional Review Board Approvals................................63

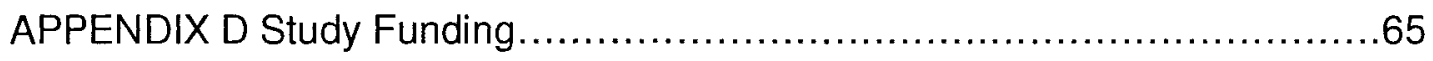




\section{LIST OF TABLES}

TITLE

PAGE

Table 4.1 Patient Sample: Enrollment and Attrition...........................23

Table 4.2 Weighted $k$ coefficients for each assessment from T1-T9 .............27

Table 4.3 Differences in CPOT scores with patient at rest (T1, T4 and T7) compared to the same patients scores during repositioning (T2, T5 and $\mathrm{T} 8 \mathrm{respectively) \ldots \ldots \ldots \ldots \ldots \ldots \ldots \ldots \ldots \ldots \ldots \ldots \ldots \ldots \ldots \ldots \ldots \ldots \ldots \ldots \ldots \ldots \ldots \ldots \ldots \ldots}$

viii 


\section{LIST OF FIGURES}

TITLE

PAGE

Figure 2.1 Spectrum of Body Movements Indicative of Pain......................11

Figure 3.1 Diagram of Study Design and Data Collection......................17

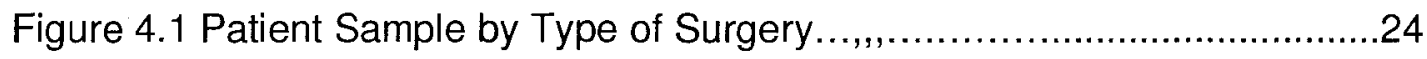

Figure 4.2 Patient Sample by Gender......................................24

Figure 4.3 Sequence of Patient CPOT Scores at Each Assessment Time 1

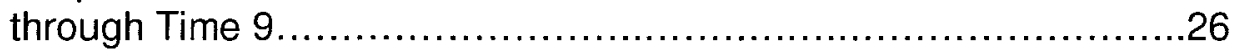




\title{
ABSTRACT \\ THE VALIDITY AND RELIABILITY OF THE CRITICAL CARE PAIN OBSERVATION TOOL [CPOT]: A PILOT [REPLICATION] STUDY
}

by

Kathleen M Keane RN, BSN, CCRN

University of New Hampshire, May, 2009

\begin{abstract}
Because critically ill patients are often not able to self report the presence of pain, an observer rating scale, the Critical Care Pain Observation Tool (CPOT) was developed for pain assessment of critically ill patients. This research examines the reliability and validity of the CPOT via replication of the original research study that developed the tool. Utilizing a repeated measures design, two nurse observers used the CPOT to score patient pain behaviors during rest, with repositioning and after repositioning. Results show fair to almost perfect interrater reliability and good discriminant validity of the instrument. The Critical Care Pain Observation Tool is a promising instrument for assessment of pain in critically ill patients.
\end{abstract}




\section{CHAPTER 1}

\section{INTRODUCTION}

The science of pain assessment and pain management is dynamic, complex, challenging and still evolving (McCaffery \& Pasero, 1999; Melzack, 2005; Puntillo, et al., 2001; Walder \& Tramer, 2004). An individual's response to pain is not simply that of a physical response but it is also a perceptual response; pain is considered to be a complex multifaceted phenomenon that encompasses cognitive, sensory, behavioral, physiologic, and affective dimensions (Melzack, 2005).

The health sciences have wrestled with the issue of how best to understand a patient's pain experience. There is general consensus that the experience of pain is individual, subjective and complex and that only patients' themselves can accurately measure their pain experience; this is referred to as a patient's self report ("Clinical Practice Guidelines for the Sustained Use of Sedatives and Analgesics in the Critically III Adult," 2002; K. Herr, et al., 2006; McCaffery \& Pasero, 1999). McCaffery's (McCaffery \& Pasero, 1999) definition of pain is often quoted in this context and utilized in the clinical setting; she states "Pain is whatever the experiencing person says it is, existing whenever he says it does" (p17).

The problem facing health practitioners is that certain vulnerable populations of patients are not able to self report ("Clinical Practice Guidelines for 
the Sustained Use of Sedatives and Analgesics in the Critically III Adult," 2002; K. Herr, et al., 2006); one such population of patients includes critically ill patients. Over the past decade, multiple studies have recognized that pain is prevalent in this population (del Barrio, Lacunza, Armendariz, Margall, \& Asiain, 2004; Johnson, St John, \& Moyle, 2006; McCaffery \& Pasero, 1999; Nelson, et al., 2001; Rotondi, et al., 2002; Thomas, 2003) and is often under recognized, under assessed and under treated (Gelinas, Fortier, Viens, Fillion, \& Puntillo, 2004; Marquie, et al., 2003; McCaffery \& Pasero, 1999; Puntillo, et al., 2001; StanikHutt, Soeken, Belcher, Fontaine, \& Gift, 2001). The consequences of untreated pain are profound not just for the individuals themselves but for our society as a whole (Gelinas, et al., 2004; Jones, Griffiths, Humphris, \& Skirrow, 2001; Marcario, 2006; Mularski, et al., 2006; Stein-Parbury \& McKinley, 2000). In retrospective interviews with patients who lived the experience of mechanical ventilation in the intensive care setting, patients reported pain due to the presence of the endotracheal tube (ETT) as well as pain related to endotracheal suctioning, coughing and repositioning(Stein-Parbury \& McKinley, 2000). A national study of 169 hospitals found that repositioning was described by Intensive Care Unit (ICU) patients to be the most painful procedure they experienced (Puntillo, et al., 2001). Patients also report long term psychological effects from the stressors of their ICU experience and indeed Post Traumatic Stress Disorder (PTSD) is recognized as a potential sequelae of long term intubation (Jones, et al., 2001). 
On a daily basis, clinicians and bedside nurses in intensive care settings make decisions about the pain experience of critically ill patients who are mechanically ventilated and unable to self report. At the time of assessment and treatment of pain in this population the gold standard of patient self report is not available to the clinician. So, based on the recommendations of current guidelines, clinicians practice the science of observing the patient for cues that indicate the patient may be experiencing pain("Clinical Practice Guidelines for the Sustained Use of Sedatives and Analgesics in the Critically III Adult," 2002; K. Herr, et al., 2006).

Interdisciplinary clinical guidelines have called for the development of standardized instruments to aid in the assessment of pain in those who cannot self report. In response to this need, new tools have been developed to aid the clinician in assessment of pain in critically ill patients (Gelinas, Fillion, Puntillo, Viens, \& Fortier, 2006; Payen, et al., 2001; Puntillo, Stannard, Miaskowski, Kehrle, \& Gleeson, 2002). The charge of nursing research at this point in time is to further test and validate the instruments under development and recommend an instrument for general clinical use.

This thesis study is a replication of the original study which developed one of these instruments, the Critical Care Pain Observation Tool or CPOT (Gelinas, et al., 2006). The purpose of this replication study is to add to the general body of knowledge known about the CPOT instrument via exploration of the reproducibility of the original findings [henceforth referred to as the Gelinas CPOT reference study]. The aim of this study is to contribute to the process of 
examining the validity and reliability of the CPOT instrument and to contribute to the process of bringing the instrument forward for use in the clinical setting. 


\section{CHAPTER 2}

\section{LITERATURE REVIEW}

The purpose of this literature review is to explore the topic of pain assessment in the critically ill patient who cannot self report. Two questions are investigated; they are: 1 . What are the indicators or classes of indicators that indicate to a clinician that the critically ill patient is having pain? and 2 . Is there a reliable and valid tool that standardizes the assessment of pain in this specific population of patients?

\section{Search Methodology}

In accordance with a holistic approach to the topic two searches were conducted, seeking articles from both quantitative and qualitative paradigms. Using multiple databases ((Academic Search Premier, CDSR, CINAHL, PreCINAHL, Psych MEDLINE, and Health Source: Nursing/ Academic Edition, PsycARTICLES and PsycINFO), searches were carried out for articles published in English from 1990 to the 2008

The first search focused on articles from the quantitative perspective and resulted in a total of 77 articles. Search terms used included combinations of the following terms: pain, pain assessment, critically ill, intubated, mechanically ventilated, non verbal, self report and communication. Twenty six articles met inclusion criteria for this review; 19 were published between 2000 and 2007 . The other 7 were seminal articles published in the 1990's. Clinical guidelines that 
addressed the topic were included in the review if they were evidence based and included supportive evidence in the review (Melynk, 2005). Of the 26 articles reviewed, 17 were from nursing journals and 9 were from medical journals.

The second search focused on articles from the qualitative perspective and resulted in a total of 13 articles. Search terms used included combinations of the following terms: patient attitudes, mechanical ventilation, intensive care, and lived experience. Four articles from nursing journals met inclusion criteria for this review, all were published between 2000 and 2006.

\section{Inclusion and Exclusion Criteria}

The criterion for inclusion in this review includes:

1. Material published in English.

2. Studies published between 2000 and 2009 (exceptions noted).

3. Research from peer reviewed journals that focuses on and seeks to describe the acute pain experiences of cognitively intact adult intensive care patients.

The criteria for exclusion in this review include:

1. Cognitively impaired patients or patients with chronic pain

2. Non English materials

3. Articles such as editorials, case studies and historical or general informational articles.

4. Articles that did not focus on the above cited patient experiences 
The articles reviewed in this literature review are summarized (see Appendix A). The table headings in the appendix serve to delineate the key areas of each article's contribution in a format that was logical to the reader and that provided a sense of the historical development of the research topic. The generalizability of the quantitative studies can be inferred from sample sizes, sampling methods and inclusion criteria of individual studies. As the problem studied is descriptive in nature many of the study designs were of a descriptive comparative design.

\section{Literature Review Results}

The literature reviewed included a preponderance of nursing scholarly articles. A review of the qualitative studies can help clinicians understand that the experience of mechanical ventilation and critical illness is fraught with pain and anxiety for patients (del Barrio, et al., 2004; Hupcey, 2000; Hupcey \& Zimmerman, 2000; Johnson, et al., 2006). Hupcey and Zimmerman (2000) describe the psychosocial needs of safety and security for this population as well as the 'need to know', a phrase that is emblematic of the patient's search for information that can help make sense of his illness experience. Patients turn to their families and to their nurse care givers for information and support during critical illness.

Unsurprisingly, a broad theme that emerges in the literature is that inferring pain intensity via observation of an individual is an inexact science. The dilemma exists: If a patient cannot self report, how then can a clinician hope to measure that patient's pain? Is it even possible, with any degree of accuracy, to observe a patient and make judgments about his level of pain? This question 
has been asked, and wrestled with in the nursing literature ((McCaffery \& Pasero, 1999), as well as in the disciplines of medicine (Melzack, 2005) and psychology (Labus, Keefe, \& Jensen, 2003; Prkachin, 1992). Work from these disciplines has substantiated that using observation skills and standardized assessment a trained observer can make accurate assessments of another individual's responses and infer the patient's pain level (Kunz, Mylius, Schepelmann, \& Lautenbacher, 2004; Labus, et al., 2003; Mateo \& Krenzischek, 1992; Puntillo, et al., 1997; Solomon, Prkachin, \& Farewell, 1997; Webb \& Kennedy, 1994). So, while observational methods of inferring pain are an imperfect form of measurement they do provide clinicians with a basis for treatment of pain in the critically ill adult. Seminal nursing research in the 1990's (Mateo \& Krenzischek, 1992; Webb \& Kennedy, 1994) described pain behaviors in the clinical setting; further research (Puntillo, et al., 1997) elegantly demonstrated that nurses can and do observe patient responses, intuit the patient's pain level and make clinical decisions based on assessment. While subjective assessments can be made with some accuracy, it is important to note that the trend of underestimating a patient's pain level can be present, particularly when the patient's pain level is more intense (Kunz, et al., 2004; Mateo \& Krenzischek, 1992; Prkachin, Berzins, \& Mercer, 1994; Puntillo, et al., 1997; Sjostrom, Dahlgren, \& Haljamae, 2000; Webb \& Kennedy, 1994; Wilson \& McSherry, 2006). Labus (2003) found correlates between behaviors and presence of pain were strengthened by assessing acute pain and the timeliness of that assessment to the behavior. Current consensus is that clinicians can infer pain is present in patients that can 
not self report via observation of behavioral and physiologic indicators ("Clinical Practice Guidelines for the Sustained Use of Sedatives and Analgesics in the Critically III Adult," 2002; K. Herr, et al., 2006).

Initially, specific behavioral pain indicators were generated out of expert clinical opinion; further work has explored the validity and clinical utility of these indicators as a part of current instrument studies (Assaoui, Zeggwagh, Zekraoui, Abidi, \& Abouqal, 2005; Erdek \& Pronovost, 2004; Feldt, 2000; Gelinas, Fillion, \& Puntillo, 2009; Gelinas, et al., 2006; Gelinas, et al., 2004; Gelinas \& Johnston, 2007; Kwekkeboom \& Herr, 2001; Payen, et al., 2001; Puntillo, et al., 1997; Puntillo, et al., 2002; Young, Siffleet, Nikoletti, \& Shaw, 2006). There are a broad range of behavioral indicators that show that pain being present in an individual; multiple studies have indicated that expressed pain behaviors of an individual can change over time (Mateo \& Krenzischek, 1992; Puntillo, et al., 1997; Webb \& Kennedy, 1994). The behaviors most likely to indicate pain are composite measures of facial expression (i.e. the facial components of a grimace), body posture (i.e. a range of behaviors that could suggest irritability or guarding) and vocalizations. The use of physiologic signs (heart rate, blood pressure and respiratory rate) of autonomic stress as an indicator of pain is controversial, but may be informative ("Clinical Practice Guidelines for the Sustained Use of Sedatives and Analgesics in the Critically III Adult," 2002).

One of the most evocative indicators of pain is facial expression. There is consistent support in the literature that one of the clearest and most definitive indicators of pain is the grimace (Dalton, Brown, Carlson, McNutt, \& Greer, 1999; 
Hadjistavropoulos, LaChapelle, Hadjistavropoulos, Green, \& Asmundson, 2002; Prkachin, 1992). There are self report instruments that have been developed based on facial expression for adults (K. A. Herr, Mobily, Kohout, \& Wagenaar, 1998; Kim \& Buschmann, 2006; Stuppy, 1998; Taylor \& Herr, 2002). Instruments designed for observed assessment of pain in the non verbal intubated patient include this indicator (Gelinas, et al., 2006; Odhner, Wegman, Freeland, Steinmetz, \& Ingersoll, 2003; Payen, et al., 2001; Puntillo, et al., 2002).

A spectrum of body movements is indicative of a pain state. In reviewing the behaviors it can be useful to describe the continuum of body movement as ranging from behaviors suggestive of irritability to those of guarding. Based on a synthesis of findings from this literature review, Figure 2.1 was developed to illustrate the spectrum of body movements that are indicative of pain. 
FIGURE 2.1

Spectrum of Body Movements Indicative of Pain

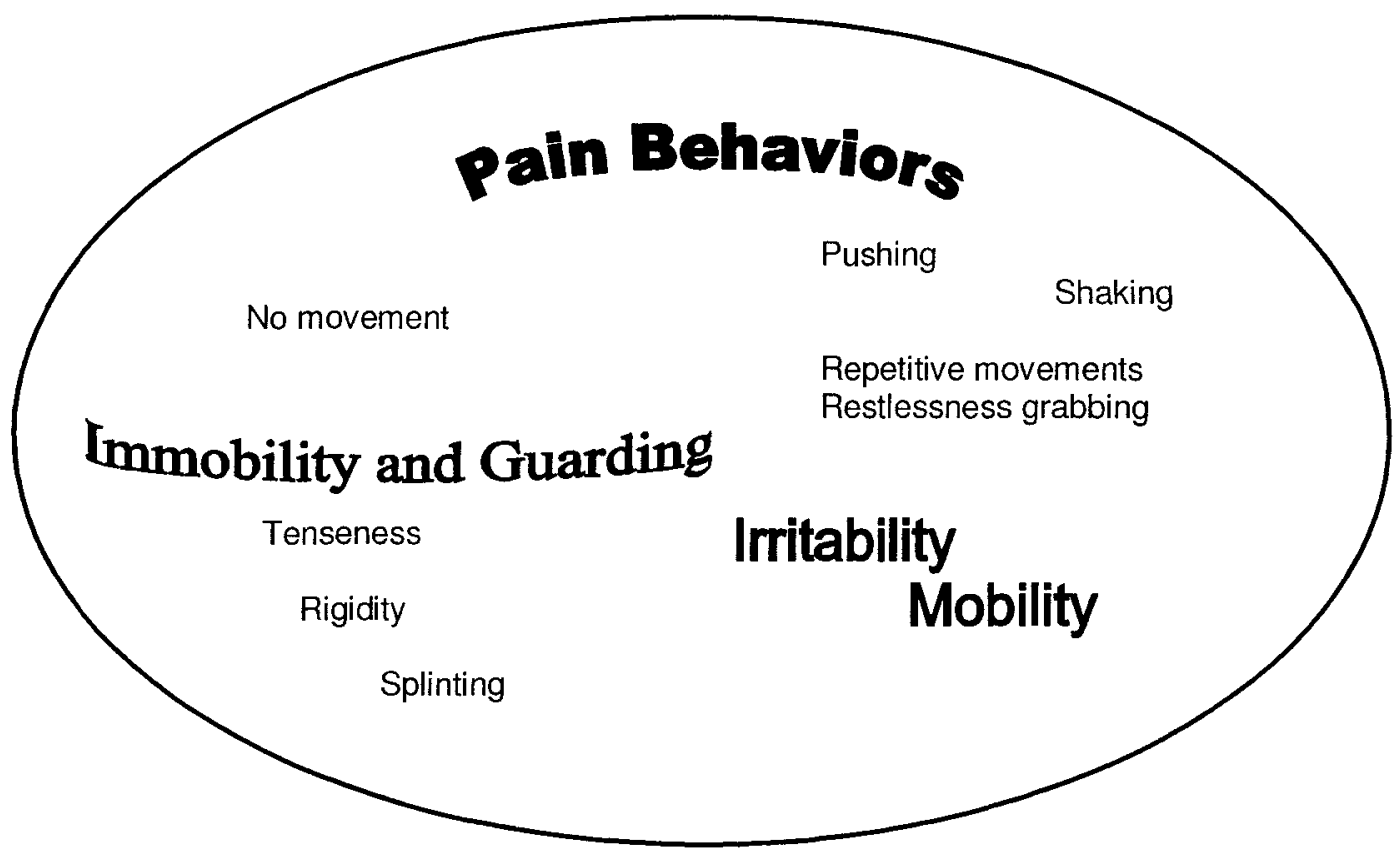

In most cases, mechanically ventilated patients cannot vocalize, thus this assessment parameter has evolved into assessment of ventilator synchrony; and as such is evolving in terms of description in the literature. There are multiple ways to evaluate dysynchrony on a ventilator. (Gelinas, et al., 2006; Gelinas, et al., 2004; Payen, et al., 2001)

There is still considerable controversy on the usefulness measures of autonomic stress (i.e. physiologic indicators such as heart rate, blood pressure and respiratory rate) as indicators of pain. The evidence does not support using physiologic indicators exclusively for pain assessment; the best that can be said at this point is they provide additive information and may be informative to the 
clinician; however, it is without question that pain can be present in the absence of any physiologic indicator.

Hence, one finds there are four broad themes of assessment that are rooted in the empirical evidence and can be classified into the following four categories: these are facial expression, body posture, vocalization and ventilator synchrony and physiologic signs. Further research is needed to fully describe the pain assessment indicators related to ventilator synchrony.

Early work by Mateo\& Krenzischek (1992) and Webb \& Kennedy (1994) describe pain behaviors in the clinical setting; Puntillo's work goes on to examine the relationship of nurse's assessments of pain indicators to the actual self report of patients and the subsequent amount of opioid administered (Puntillo, et al., 1997). Clinically valid and reliable assessment tools are still in the process of development. Puntillo (2000) developed an algorithm (P.A.I.N. Notation) which seeks to standardize the practice of pain assessment by walking the clinician through the assessment of pain indicators. This tool proved accurate but was deemed by some clinicians as too lengthy to be practical for use in the clinical setting. Two other instruments have been developed to for use in assessing pain in the mechanically ventilated critically ill patient who cannot self report. These are the Behavioral Pain Scale (BPS) (Payen, et al., 2001) and the CPOT (Gelinas, et al., 2006). Appendix B lists and summarizes the properties of these three instruments.

Each of these instruments needs further testing of validity and reliability before one can be recommended for general clinical use. The charge of nursing 
research at this point in time is to test and validate the instruments under development and recommend an instrument for general clinical use. The CPOT is a promising instrument for use in the clinical setting because of its ease of use. In addition, because the CPOT was developed by correlating a patient's self report to the instrument score, the validity of the instrument is supported by a strong methodologic basis. For these reasons, this study chose to examine the validity and reliability of the CPOT instrument through the process of replication of the Gelinas CPOT reference study.

\section{Conceptual Framework}

As in the Gelinas CPOT reference study, Melzack's (2005) Neuromatrix Theory of Pain is the conceptual framework used to approach this investigation. The Neuromatrix Theory acknowledges the complexity of pain experience by proposing that not simply sensory experience but perceptual elements frame the experience of pain. This theory is evolving but serves to explain the multidimensional nature of acute pain as well as pain which is chronic in nature.

\section{Problem Statement}

Despite repeated calls for a reliable and valid tool that accurately assesses pain in the critically ill patient there is currently no generally accepted tool for this population ("Clinical Practice Guidelines for the Sustained Use of Sedatives and Analgesics in the Critically III Adult," 2002; K. Herr, et al., 2006). The use of a standardized instrument (Erdek \& Pronovost, 2004) has been demonstrated to improve pain assessment. Tools with clinical utility are in the early stage of development. In order to better assess and treat pain in the 
critically ill, further testing is needed to determine a reliable and valid instrument. This research seeks to add to the present body of knowledge and examine the reliability and validity of the Critical Care Pain Observation Tool (CPOT) via replication of the initial study. The CPOT instrument was originally developed in the French language and forward-backward translated into English (Gelinas, Harel, Fillion, Puntillo, \& Johnston, 2009). The CPOT was developed for pain assessment of the critically ill patients and has been tested for reliability and content, criterion and discriminant validity in one study of 105 patients who underwent open heart surgery. One additional study examined the validity and reliability of the instrument in 55 adult ICU patients (Gelinas \& Johnston, 2007).

\section{Research Question}

This replication study seeks to discover if the original findings of Gelinas et al. (2006) can be reproduced in a similar setting with a similar population of patients. The research questions asked are:

1. What are the measurements of the discriminant and criterion validity of the CPOT instrument?

2. What is the measurement of reliability of the CPOT instrument?

The significance of this replication study is that it adds to the two studies that have examined this instrument and contributes to the process of translating the use of this instrument to the clinical setting. Improved pain assessment results in improved pain management of critically ill patients. 


\section{CHAPTER 3}

\section{METHODOLOGY}

\section{Study Design}

This quantitative study had a repeated measures design. The CPOT instrument was utilized to assess post operative pain in open heart surgery patients. The standard care of such patients involves recovery from anesthesia and removal of ventilatory assistive devices, such as an endotracheal tube. The presence of an endotracheal tube prevents patients from vocalizing or phonating. Patients are often not interactive and may be unable to self report pain during this period. Patients are repositioned to prevent pressure ulcers and facilitate drainage from tubes in the thorax and are routinely assessed for pain and medicated for pain throughout this period.

Each study patient had assessments taken with the CPOT instrument at three different times on the day of their surgery (referred to as postoperative day $0)$. Two nurse observers performed the assessments independently and were blinded to each other's scores. If patients were interactive, they were asked to self report their pain scores.

\section{Setting}

This study was conducted in a large (> 600 beds) teaching hospital located in the northeastern United States. As in the Gelinas CPOT research 
study being replicated, data was collected on postoperative open heart surgery patients in a cardiothoracic intensive care setting.

\section{Patient Sample and Population}

A convenience sample was utilized; 23 patients were enrolled. The patient population consisted of adults that were scheduled for open-heart surgery

procedures. Inclusion criteria were that patients (a) be greater than 21 years of age (b) be English speaking patients and (c) require the need for cardiothoracic surgery. Exclusion criteria were (a) a left ventricular ejection fraction of less than $25 \%$, (b) neuromuscular blockers following surgery (c) acute hemodynamic complications after surgery (d) alcohol or drug dependence, and (e) a history of medical treatment for chronic pain. For the purposes of this study, patients were expected to progress to endotracheal tube extubation within eight hours of arrival in the intensive care unit. For this reason, inclusion and exclusion criteria were designed to enroll patients that would be at low risk for postoperative complications. Patients were enrolled from September of 2008 until February of 2009.

\section{Study Procedure}

Figure 3.1 illustrates the process of enrolling patients and performing three consecutive assessments on post operative day zero. 
FIGURE 3.1

Diagram of Study Design and Data Collection

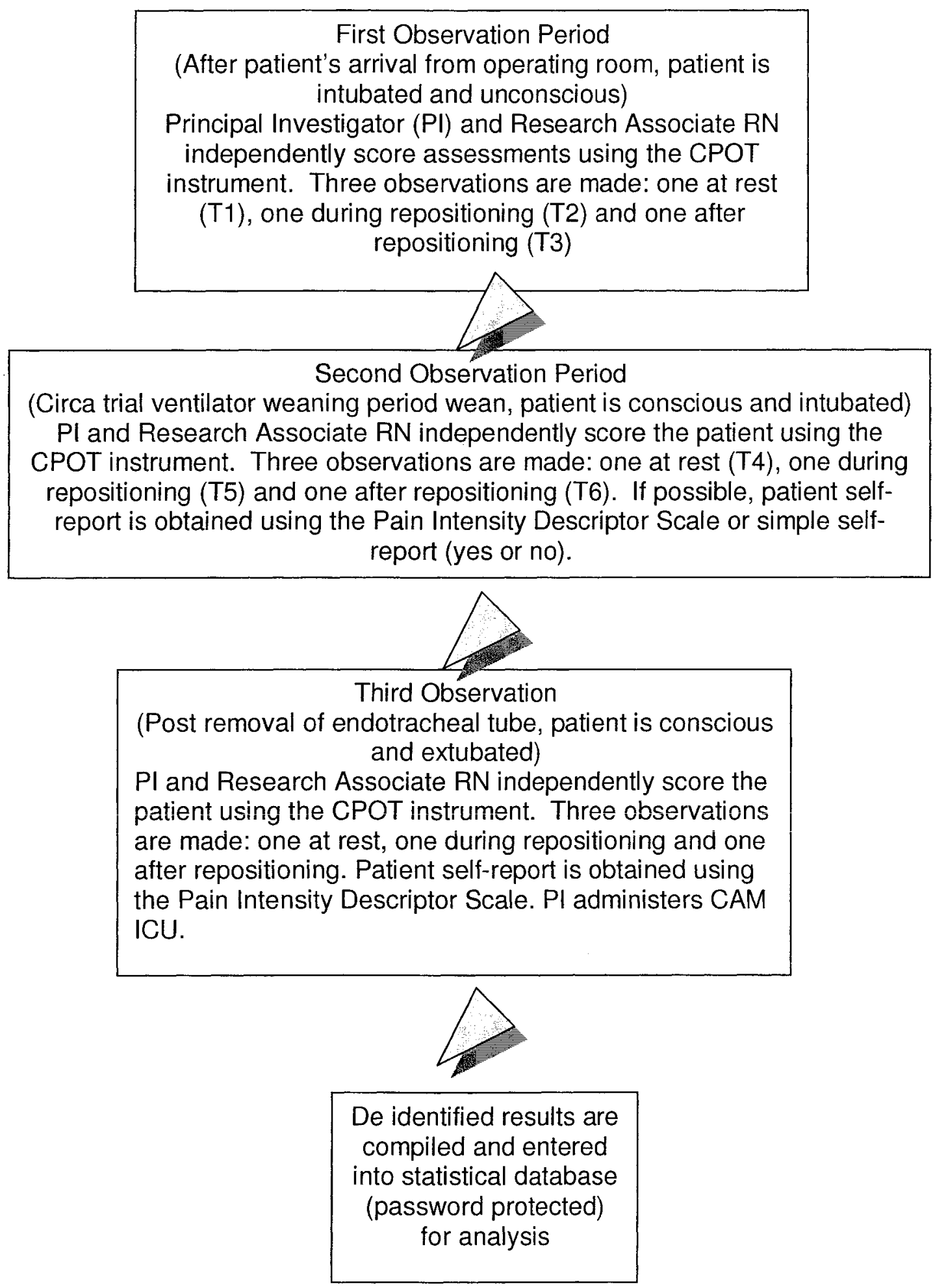


Along with the principal investigator, seven staff nurses participated in the reliability testing of the CPOT instrument. In reliability testing, two nurses rate the patient's pain using the CPOT scale; each nurse is blinded to the scoring of the other nurse. Prior to evaluating patients in the study, each nurse participant received a standardized form of instruction regarding usage of the CPOT instrument. The instruction consisted of reviewing video taped vignettes that were developed by the original author of the CPOT instrument. These practice vignette scores were then compared to the scores supplied by the instrument's author with a goal of attaining scores that correlated completely with the scoring of the vignettes by the original author of the instrument.

\section{Patient Enrollment}

Patients were identified as prospective study subjects through one of two methods. In the first method, patients were identified by the Pl's review of the weekly operating room schedule for open-heart surgery patients at the hospital. Following a review of the chart to ascertain whether they met inclusion criteria, pre operative in-house patients were invited to participate. In the second method, patients were identified as potential participants when completing their scheduled preadmission screening tests at the hospital. Following a review of the chart to ascertain whether they met inclusion criteria, these pre operative out-patients were invited to participate in the study. 


\section{Research Ethics}

The PI was responsible for informed consent of patients. This study received expedited approval from the Maine Medical Center Institutional Review Board as well as the Institutional Review Board of the University of New Hampshire prior to beginning data collection. Patients were informed there was no direct benefit to participating in this study. There was no risk to patient participation in the study other than the slight risk of loss of confidentiality of the patient's private information. Every effort was made to protect patient confidentiality. Data was collected in a de identified manner and the master log that cross-referenced patient identifiers with patient data was kept locked in a cabinet in the cardiothoracic unit that is reserved for research purposes. At the completion of the study, the log of patient identifiers was destroyed. For each informed consent, one copy was given to the patient, one copy was placed in the patients chart and the original signed document was placed in a regulatory binder that is stored in a locked cabinet in the hospital's Nursing Research Department.

In addition to the principal investigator, the nurses that participated in the reliability testing of this instrument completed an on-line training program on ethics and clinical research via a hospital training program.

\section{Study Instrumentation}

The instrument studied was the CPOT tool (Gelinas, et al., 2006); it was developed to assess pain in critically ill patients who cannot self-report. The CPOT is an assessment scale that has shown good reliability, validity and clinical applicability in initial studies. Evaluative indicators include facial expression, body 
movements, muscle tension and compliance with the ventilator or vocalizations. Each indicator can be scored according to scale criteria as a 0,1 , or 2 and the scale scoring has a total range of 0 to 8 .

As in the Gelinas CPOT reference study, patients in the study were screened for delirium post extubation; those that screened positive for delirium were excluded from the study. The Confusion Assessment Method Intensive Care Unit (CAM-ICU) was used to screen for delirium. The CAM-ICU (Ely, et al., 2001) instrument has been well studied and validated for use in the critically ill population. The sedation level of patients were measured using the Ramsay scale (Ramsay, Savege, Simpson, \& Goodwin, 1974). The scale ranges from 1 to 6 and assesses patient responsiveness and agitation; a score of 5 or 6 is indicative of a decreased level of consciousness and a minimally responsive patient.

The Pain Intensity Descriptive Scale (PIDS) is a self-report instrument that patients can use to rate their level of pain. The scale consists of five verbal descriptors of pain (none, mild, moderate, severe and unbearable). This verbal descriptor scale has been previously studied and has been shown to be a reliable and valid instrument for pain measurement in postoperative patients (Mateo \& Krenzischek, 1992).

\section{Analytical Methods}

De identified data was collected and statistical calculations were conducted in MedCalc for Windows, version 10.02.0 (MedCalc Software, 
Mariakerke, Belgium) and version 15.0 of SPSS for Windows (SPSS Inc, Chicago, III.).

Psychometric evaluation of instrument validity consisted of evaluation of the discriminant validity and criterion validity. Discriminant validity of an instrument refers to the ability of an instrument to measure one intended variable and not another in this case; pain versus no pain. Discriminant validity of the CPOT instrument was tested by comparing the mean scores of a periods at rest a (nonnocioceptive period) to the mean score from a period of discomfort (repositioning is considered a nocioceptive procedure). Paired Student's t- tests were performed to compare the mean scores of the testing periods $\mathrm{T} 1$ and $\mathrm{T} 2$, T4 and T5, and T7 and T8, respectively.

Criterion validity refers to the ability of an instrument to measure the phenomena of interest, in this case, the measurement of pain. Criterion validity compares the measurement variable to a reference measurement of the same variable. In this study the nurse observer rated pain score was compared to the 'gold' standard of pain measurement, the patient self report. The Spearman correlation was utilized to compare the numerical score (the PIDS Scale) given by patient and the numerical CPOT Score obtained by nurse observer scoring.

Psychometric evaluation of reliability was conducted via calculation of interrater reliability with weighted kappa coefficients. Inter-rate reliability (IRR) measures the extent to which different users of the instrument can, under similar circumstances, obtain like measurements. Interrater reliability of the CPOT was measured by comparing the blinded independent assessments by two nurse 
observers at Time 1 to Time 9. Weighted kappa coefficients were calculated at each of these times. Weighted kappa measurements are able to account for the degree of congruence of measurements that have multiple items in a scale. 
CHAPTER 4

RESULTS

\section{Sample Characteristics}

The hospital charts of thirty three patients scheduled for open heart surgery were reviewed for study inclusion and exclusion criteria; twenty nine of these patients were invited to participate. Six patients declined to participate in the study. Five of these six patients stated they were too anxious to consider participation; the sixth patient stated that he was not interested in participating in research. Table 1 illustrates enrollment and attrition of subjects.

\section{TABLE 4.1}

Patient Sample: Enrollment and Attrition

\begin{tabular}{cccccc}
\hline Charts & Invited to & Patients & Patient & Patient & Total \\
Reviewed & Participate & Enrolled & Withdrew* $^{\text {Excluded** }}$ & \\
\hline 33 & 29 & 23 & 1 & 1 & 21 \\
& & & & & \\
\hline
\end{tabular}

*patient withdrew because he felt too anxious to participate

${ }^{\star *}$ patient excluded from data collection because of hemodynamic instability 
The sample demographics are illustrated in Figure 4.1 and Figure 4.2.

FIGURE 4.1

Patient Sample by Type of Surgery

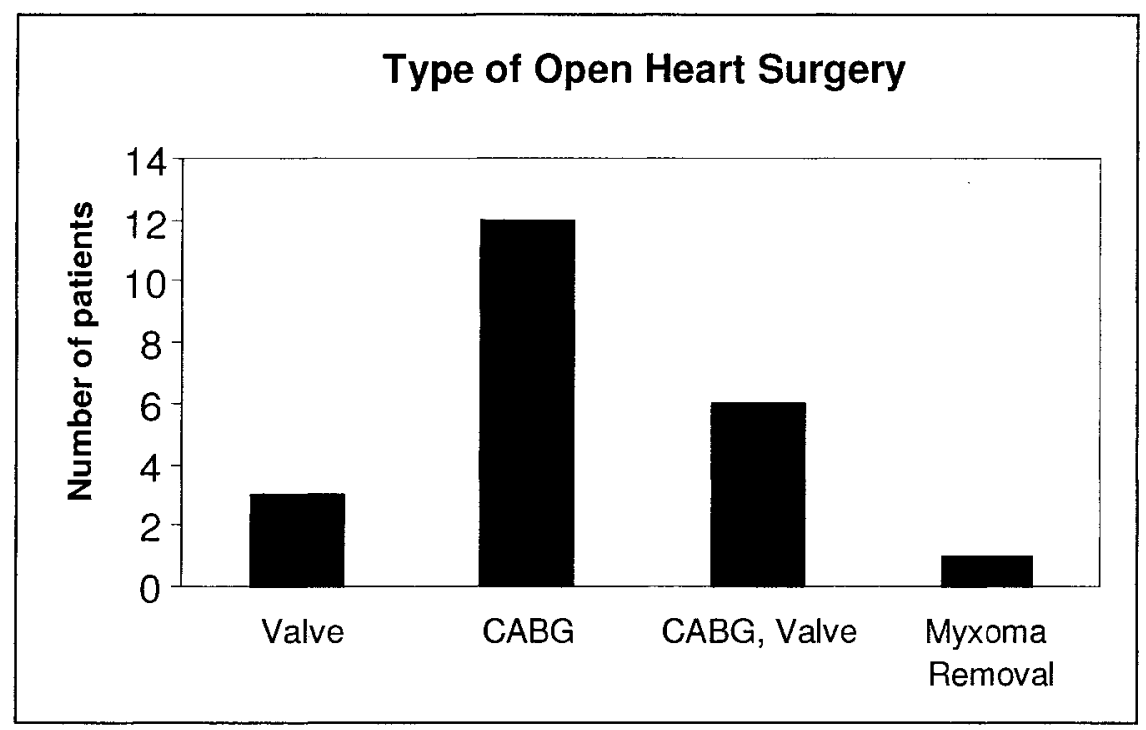

FIGURE 4.2

Patient Sample by Gender

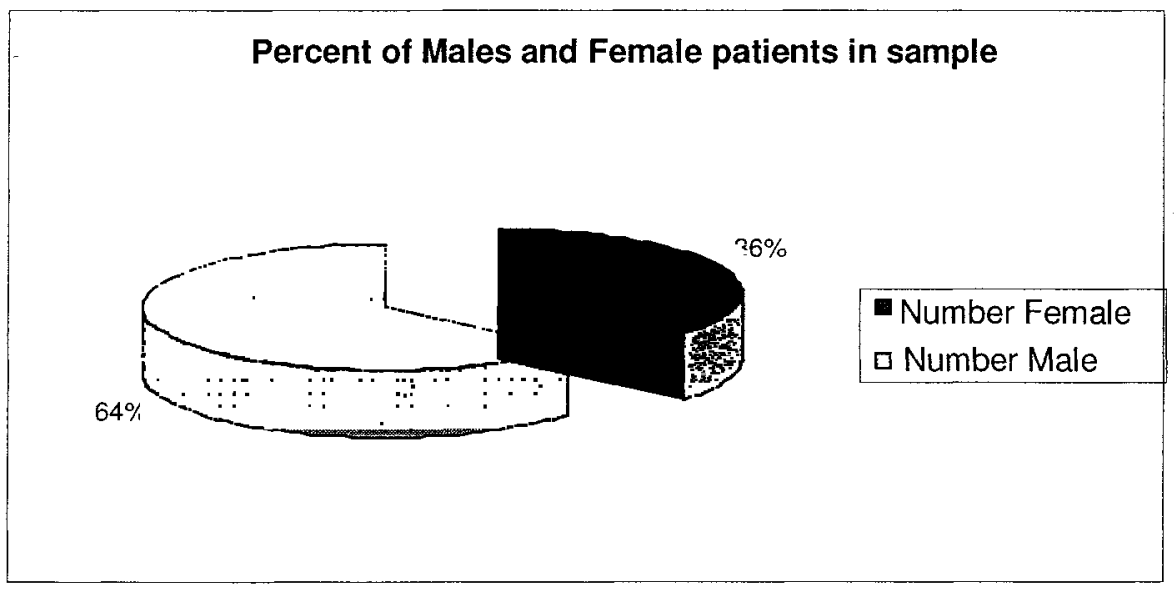

The ages of patients enrolled in the study ranged from 44 to 85 years, the mean age of patients was 64 . 


\section{Assessment Period One}

The first assessment period took place in the intensive care unit approximately one hour after the patient's arrival from the operation room. The patient's record was reviewed to ascertain that he had not received any paralytic medications post operatively. The patient was assessed with the CPOT instrument at rest (Time 1), with repositioning (Time 2) and again at rest (Time 3). Two nurse observers performed the assessment and were blinded to each other's assessment. A criterion for this time period is that the patient be intubated and unconscious. The Ramsay Scale was used to assess the level of consciousness; a score indicative of unconsciousness is 5 or 6 . Of the 21 patients assessed during this period, 15 patients met the criteria for evaluation.

\section{Assessment Period Two}

The second assessment period took place when the patient was still intubated and had become conscious, as evidenced by a Ramsey Scale score of 2,3 , or 4 . The patient was assessed with the CPOT by two nurse observers at rest (Time 4), with repositioning (Time 5) and again at rest (Time 6). In addition, the patient's self report was solicited at Time 5 when the patient was repositioned. A simple self report system was used during this time; patients were asked to indicate if pain were present or absent by nodding their head yes or no. This method of self report was used because patients were generally too sleepy to use the more complex numerical PIDS scale. Even so, only about half $(11 / 21)$ of the patients who were conscious were interactive enough to self report their pain level at this point in time. 


\section{Assessment Period Three}

The final assessment period was performed when patients were extubated and awake. Patients were assessed at rest (Time 7), during positioning (Time 8), and again at rest (Time 9). Patients were also asked to indicate if pain was present at Time 8 and to self report using the PIDS scale. Graphic representation of the mean observed CPOT scores at each assessment of T1 through T 9 are represented in Figure 4.3.

FIGURE 4.3

Sequence of Patient CPOT Scores at Each Assessment Time 1 through Time 9

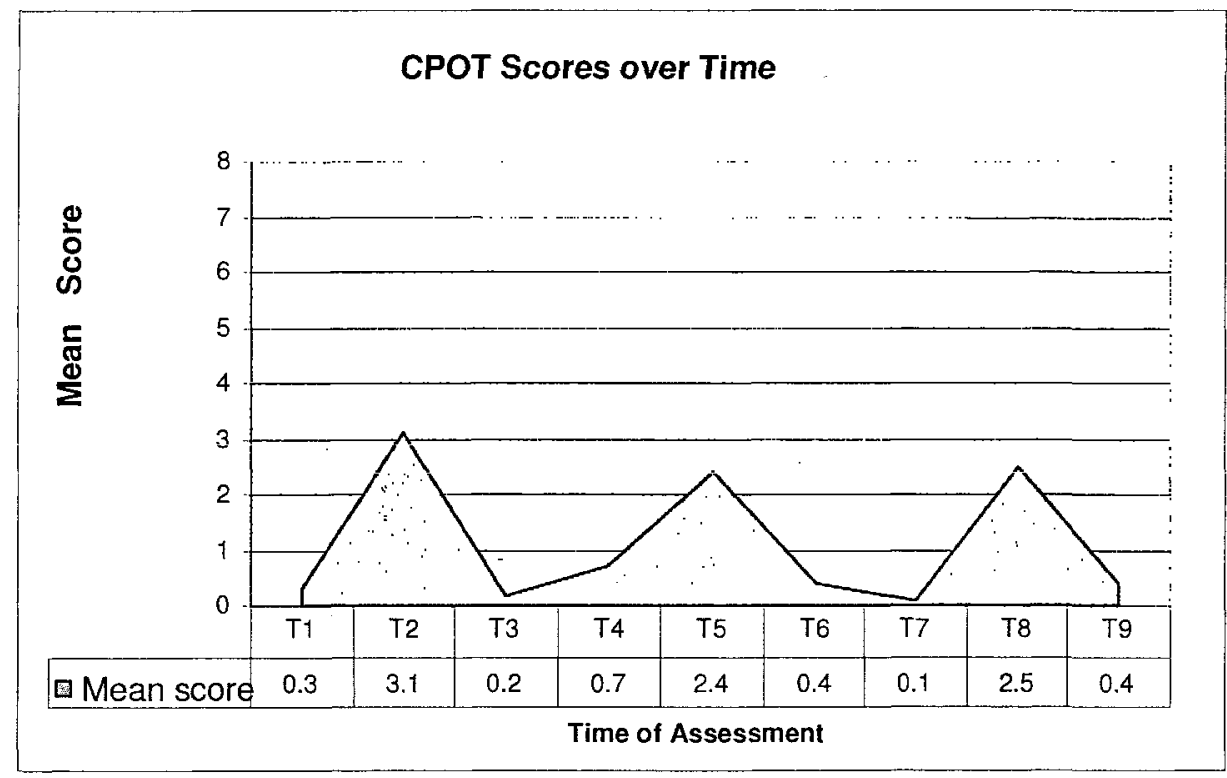




\section{Interrater Reliability}

Findings on IRR were variable; with weighted kappa coefficients ranging from 0.34 to 1.0. These weighted kappa values are a measure of how well the ratings of the nurse observers were in agreement. According to Landis and Koch (1977) these values correlate with levels of acceptability which range from fair to perfect. Interrater reliability for each assessment from Time 1 to Time 9 is illustrated in Table 4.2.

TABLE 4.2.

Weighted $k$ coefficients for each assessment from $\mathrm{T} 1-\mathrm{T} 9$

$\begin{array}{lcc}\text { Assessment } & \text { \# of patients } & \text { weighted k coefficient } \\ \text { T1 } & 15 & 1.0 \\ \text { T2 } & 15 & .72 \\ \text { T3 } & 15 & .34 \\ \text { T4 } & 21 & .61 \\ \text { T5 } & 21 & .47 \\ \text { T6 } & 21 & .56 \\ \text { T7 } & 17 & .36 \\ \text { T8 } & 17 & .57 \\ \text { T9 } & 17 & .46 \\ & \end{array}$




\section{Discriminant validity}

The CPOT tool showed a significant differences in mean scores between a non nocioceptive period, the rest periods of $\mathrm{T} 1, \mathrm{~T} 4$ and $\mathrm{T} 7$, and a period of nocioception, the positioning periods of $\mathrm{T} 2, \mathrm{~T} 5$, and $\mathrm{T} 8$ ( see Table 4.3).

\section{TABLE 4.3}

Differences in CPOT scores with patient at rest ( $\mathrm{T} 1, \mathrm{~T} 4$ and $\mathrm{T} 7)$ compared to the same patients scores during repositioning (T2, $\mathrm{T} 5$ and $\mathrm{T} 8$ respectively)

\begin{tabular}{lccccc}
\hline Assessment at & No. of & & & \multicolumn{2}{c}{$95 \%$ Confidence Interval } \\
Rest/Position & observations & $t$ & $d f$ & lower & upper \\
\hline $\mathrm{T} 1 / \mathrm{T} 2$ & 30 & $-5.784^{*}$ & 14 & -3.92543 & -1.87457 \\
& & & & & \\
$\mathrm{~T} 4 / \mathrm{T} 5$ & 40 & $-5.785^{*}$ & 20 & -2.26064 & -1.08936 \\
& & & & & \\
$\mathrm{~T} 7 / \mathrm{T} 8$ & 32 & $-7.662^{*}$ & 16 & -2.61148 & -1.51352 \\
${ }^{*} \mathrm{P}<.001$, two tailed & & & &
\end{tabular}

\section{Criterion Validity}

Because of incomplete data collection, criterion validity could not be measured by the methods used in the Gelinas reference CPOT study. 


\section{CHAPTER FIVE}

\section{DISCUSSION}

\section{Conclusions}

Sample demographics of this study were similar to the sample demographics in the Gelinas reference study. Descriptive statistics showed replicable findings of mean CPOT scores of this study in comparison to the Gelinas reference study. Mean CPOT scores in this study ranged from 0.1 to 3.1. In the Gelinas references study, mean CPOT scores ranged from 0.55 to 3.4. As the total range of scores for the CPOT instrument is 0 to 8 , the range of observed scores in both studies are skewed to the lower end of the scale and could suggest the instrument is not adequately describing (i.e. sensitive) to the pain experience of patients. Another possible explanation is simply that post anesthesia effect has muted scores in this population. Indeed, Gelinas \& Johnston (2007) found higher mean CPOT scores in a study of mixed ICU patients (trauma, post operative and medical patients).

Current work by Gelinas (Gelinas, Harel, et al., 2009) has found high specificity of the CPOT instrument, with variable (low to high) sensitivity of the instrument in the open heart surgery population. Testing in different populations of patients should help to clarify the clinical significance of CPOT scores and the utility of the instrument in practice. Testing for interrater reliability in this study showed a range of results resulting in fair to almost perfect interrater reliability with weighted kappa scores ranging from .34 to 1.0 in Time 1 to Time 9. 
Weighted kappa scores in the Gelinas reference study ranged from 0.52 to 0.88 , with interrater reliability (IRR) ranging from moderate to high. Lower IRR scores can be expected in this study as seven nurses were involved in using the instrument to evaluate IRR in comparison to two nurses in the Gelinas CPOT reference study. The interrater reliability findings of this study suggest that the instrument's interrater reliability is acceptable but variable. The nurses who participated in reliability testing were given one educational session on the instrument which consisted of reviewing videotaped patient scenarios and scoring at each time period. The scores were then reviewed with reference scores provided by the author of the CPOT instrument. During the course of this study, nurses using the scale had questions about how to score the CPOT when a patient is prompted to use a device for splinting his incision during repositioning. Inconsistencies in scoring during this type of procedure may have contributed to lower reliability scores in this study. Using repeat standardized educational programs for tool users and clarifying tool use in different clinical scenarios would be useful for clinicians and improve instrument reliability.

Testing for discriminant validity revealed a significant difference in mean scores at each testing interval. Analysis showed a statistically significant difference between scores at rest and scores with repositioning. These findings are consistent with the findings that tested discriminant validity in the Gelinas reference article. There needs to be further research work exploring the sensitivity and specificity of this instrument to evaluate if the statistical difference in mean scores is also clinically significant. 


\section{Limitations}

The potential for the presence of a confounding variable in the study should be acknowledged. Anxiety is a component of critical illness and is well documented in patient's reports of their illness experience (Rotondi, et al., 2002; Stein-Parbury \& McKinley, 2000). It is possible that some behaviors measured are related to anxiety and not pain; patient self report of anxiety was not assessed for in the process of this study.

Due to incomplete data collection, it was not possible to test for criterion validity in this study.

Potential biases of the principal investigator and study nurses could have influenced results. The small sample size of this study $(n=21)$ limits the generalizability of this study. This study was conducted on postoperative open heart surgery patients and the results should not be generalized to all intensive care patients.

\section{Implications for Practice}

This replication of the Gelinas reference study supports the reliability and discriminant validity of the CPOT instrument in assessing for pain in open heart surgery patients. A particular strength of this study is that it adds substantive information on the interrater reliability component of this instrument.

The original CPOT was developed in French and has been forwardbackward translated into English. This replication study is the first to utilize solely the English version of the instrument. Further work could continue to examine the instruments characteristics relative to the language version being used. 
The CPOT is a promising instrument for use in assessing pain in critically ill open heart surgery patients; more testing is needed in other populations of critically ill patients. The staff nurses involved in the reliability testing of the CPOT instrument related they found the instrument easy to use and time effective. Further research could explore the process of how nurses utilize the instrument in the clinical setting.

This replication study adds to two other studies that have examined this instrument and contributes to the process of translating the use of this instrument to the clinical setting. 


\section{REFERENCES}

Assaoui, Y., Zeggwagh, A. A., Zekraoui, A., Abidi, K., \& Abouqal, R. (2005). Validation of a behavioral pain scale in critically ill, sedated, and mechanically ventilated patients. Anesthesia And Analgesia, 101(5), 1470-1476. Retrieved from

http://search.ebscohost.com/login.aspx?direct=true\&db=cmed m\&AN=16244013\&site=ehost-live

Clinical Practice Guidelines for the Sustained Use of Sedatives and Analgesics in the Critically III Adult. (2002). American Journal of Health-System Pharmacy, 59(2), 150-178. Retrieved from http://search.ebscohost.com/login.aspx?direct=true\&db=aph\& AN=6504368\&site $=$ ehost-live

Dalton, J. A., Brown, L., Carlson, J., McNutt, R., \& Greer, S. M. (1999). An evaluation of facial expression displayed by patients with chest pain. Heart \& Lung: The Journal Of Critical Care, 28(3), 168-174.

del Barrio, M., Lacunza, M. M., Armendariz, A. C., Margall, M. A., \& Asiain, M. C. (2004). Liver transplant patients: their experience in the intensive care unit. A phenomenological study. [Article]. Journal of Clinical Nursing, 13, 967-976.

Ely, E. W., Inouye, S. K., Bernard, G. R., Gordon, S., Francis, J., May, L., et al. (2001). Caring for the critically ill patient. Delirium in mechanically ventilated patients: validity and reliability of the 
Confusion Assessment Method for the Intensive Care Unit (CAM-ICU). JAMA: Journal of the American Medical Association, 286(21), 2703.

Erdek, M. A., \& Pronovost, P. J. (2004). Improving assessment and treatment of pain in the critically ill. International Journal For Quality In Health Care: Journal Of The International Society For Quality In Health Care / Isqua, 16(1), 59-64.

Feldt, K. S. (2000). The checklist of nonverbal pain indicators (CNPI). Pain Management Nursing: Official Journal Of The American Society Of Pain Management Nurses, 1(1), 13-21.

Gelinas, C., Fillion, L., \& Puntillo, K. A. (2009). Item selection and content validity of the Critical-Care Pain Observation Tool for non-verbal adults. [Article]. Journal of Advanced Nursing, 65, 203-216.

Gelinas, C., Fillion, L., Puntillo, K. A., Viens, C., \& Fortier, M. (2006). Validation of the critical-care pain observation tool in adult patients. American Journai Of Critical Care: An Orfícial Publication, American Association Of Critical-Care Nurses, 15(4), 420-427.

Gelinas, C., Fortier, M., Viens, C., Fillion, L., \& Puntillo, K. (2004). Pain assessment and management in critically ill intubated patients: a retrospective study. American Journal Of Critical 
Care: An Official Publication, American Association Of CriticalCare Nurses, 13(2), 126-135.

Gelinas, C., Harel, F., Fillion, L., Puntillo, K. A., \& Johnston, C. C. (2009). Sensitivity and Specificity of the Critical-Care Pain Observation Tool for the Detection of Pain in Intubated Adults After Cardiac Surgery. Journal of Pain \& Symptom Management, 37(1), 58-67.

Gelinas, C., \& Johnston, C. (2007). Pain assessment in the critically ill ventilated adult: validation of the critical-care pain observation tool and physiologic indicators. Clinical Journal of Pain, 23(6), 497-505.

Hadjistavropoulos, T., LaChapelle, D. L., Hadjistavropoulos, H. D., Green, S., \& Asmundson, G. J. (2002). Using facial expressions to assess musculoskeletal pain in older persons. European Journal Of Pain (London, England), 6(3), 179-187.

Herr, K., Coyne, P. J., Key, T., Manworren, R., McCaffery, M., Merkel, S., et al. (2006). Pain assessment in the nonverbal patient: position statement with clinical practice recommendations. Pain Management Nursing: Official Journal Of The American Society Of Pain Management Nurses, 7(2), 44-52.

Herr, K. A., Mobily, P. R., Kohout, F. J., \& Wagenaar, D. (1998). Evaluation of the Faces Pain Scale for use with the elderly. The Clinical Journal Of Pain, 14(1), 29-38. 
Hupcey, J. E. (2000). Feeling safe: the psychosocial needs of ICU patients. Journal Of Nursing Scholarship: An Official Publication Of Sigma Theta Tau International Honor Society Of Nursing / Sigma Theta Tau, 32(4), 361-367.

Hupcey, J. E., \& Zimmerman, H. E. (2000). The need to know: experiences of critically ill patients. American Journal of Critical Care, 9(3), 192-198.

Johnson, P., St John, W., \& Moyle, W. (2006). Long-term mechanical ventilation in a critical care unit: existing in an uneveryday world. [Article]. Journal of Advanced Nursing, 53, 551-558.

Jones, C., Griffiths, R. D., Humphris, G., \& Skirrow, P. M. (2001). Memory, delusions, and the development of acute posttraumatic stress disorder-related symptoms after intensive care. Critical Care Medicine, 29(3), 573-580.

Kim, E. J., \& Buschmann, M. T. (2006). Reliability and validity of the Faces Pain Scale with older adults. [Article]. International Journal of Nursing Studies, 43, 447-456.

Kunz, M., Mylius, V., Schepelmann, K., \& Lautenbacher, S. (2004). On the relationship between self-report and facial expression of pain. The Journal Of Pain: Official Journal Of The American Pain Society, 5(7), 368-376. 
Kwekkeboom, K. L., \& Herr, K. (2001). Assessment of pain in the critically ill. Critical Care Nursing Clinics Of North America, 13(2), 181-194.

Labus, J. S., Keefe, F. J., \& Jensen, M. P. (2003). Self-reports of pain intensity and direct observations of pain behavior: when are they correlated? [Article]. Pain (03043959), 102, 109.

Landis, J. R., \& Koch, G. G. (1977). The measurement of observer agreement for categorical data. Biometrics, 33(1), 159-174.

Marcario, A. (2006). Assessing the Costs of Postoperative Pain Management Variability in Economic Analyses. Compass website, from

http://postoppain.com/html/pop/pd print.xml?article+content articles

Marquie, L., Raufaste, E., Lauque, D., MarinÃ@, C., Ecoiffier, M., \& Sorum, P. (2003). Pain rating by patients and physicians: evidence of systematic pain miscalibration. [Article]. Pain 102, 289.

Mateo, O. M., \& Krenzischek, D. A. (1992). A pilot study to assess the relationship between behavioral manifestations and self-report of pain in postanesthesia care unit patients. Journal Of Post Anesthesia Nursing, 7(1), 15-21.

McCaffery, M., \& Pasero, C. (1999). Pain: clinical manual. St. Louis, MO: Mosby-Year Book. 
Melynk, B. a. F.-O., Ellen (2005). Evidence-based practice in nursing \& healthcare: a guide to best practice

Philadelphia: Lippincott Williams\& Wilkins.

Melzack, R. (2005). Evolution of the Neuromatrix Theory of Pain. The Prithvi Raj Lecture: Presented at the Third World Congress of World Institute of Pain, Barcelona 2004. [Article]. Pain Practice, 5, 85-94.

Mularski, R. A., Curtis, J. R., Billings, J. A., Burt, R., Byock, l., Fuhrman, C., et al. (2006). Proposed quality measures for palliative care in the critically ill: a consensus from the Robert Wood Johnson Foundation Critical Care Workgroup. Critical Care Medicine, 34(11 Suppl), S404-411.

Nelson, J. E., Meier, D. E., Oei, E. J., Nierman, D. M., Senzel, R. S., Manfredi, P. L., et al. (2001). Self-reported symptom experience of criticaliy ill cancer patients receiving intensive care. Critical Care Medicine, 29(2), 277-282.

Odhner, M., Wegman, D., Freeland, N., Steinmetz, A., \& Ingersoll, G. L. (2003). Assessing Pain Control in Nonverbal Critically III Adults. Dimensions of Critical Care Nursing, 22(6), 260-267.

Payen, J. F., Bru, O., Bosson, J. L., Lagrasta, A., Novel, E., Deschaux, I., et al. (2001). Assessing pain in critically ill sedated patients by using a behavioral pain scale. Critical Care Medicine, 29(12), 2258-2263. 
Prkachin, K. M. (1992). The consistency of facial expressions of pain: a comparison across modalities. Pain, 51(3), 297-306.

Prkachin, K. M., Berzins, S., \& Mercer, S. R. (1994). Encoding and decoding of pain expressions: a judgement study. Pain, 58(2), 253-259.

Puntillo, K. A., Miaskowski, C., Kehrle, K., Stannard, D., Gleeson, S., \& Nye, P. (1997). Relationship between behavioral and physiological indicators of pain, critical care patients' selfreports of pain, and opioid administration. Critical Care Medicine, 25(7), 1159-1166.

Puntillo, K. A., Stannard, D., Miaskowski, C., Kehrle, K., \& Gleeson, S. (2002). Use of a pain assessment and intervention notation (P.A.I.N.) tool in critical care nursing practice: nurses' evaluations. Heart \& Lung: The Journal Of Critical Care, 31(4), 303-314.

Puntillo, K. A., White, C., Morris, A. B., Perdue, S. T., Stanik-Hutt, J., Thompson, C. L., et al. (2001). Patients' perceptions and responses to procedural pain: results from Thunder Project II. American Journal of Critical Care, 10(4), 238-251.

Ramsay, M. A., Savege, T. M., Simpson, B. R., \& Goodwin, R. (1974). Controlled sedation with alphaxalone-alphadolone. British Medical Journal, 2(5920), 656-659. 
Rotondi, A. J., Chelluri, L., Sirio, C., Mendelsohn, A., Schulz, R., Belle, S., et al. (2002). Patients' recollections of stressful experiences while receiving prolonged mechanical ventilation in an intensive care unit. Critical Care Medicine, 30(4), 746-752. Sjostrom, B., Dahlgren, L. O., \& Haljamae, H. (2000). Strategies used in post-operative pain assessment and their clinical accuracy. [Article]. Journal of Clinical Nursing, 9, 111-118.

Solomon, P. E., Prkachin, K. M., \& Farewell, V. (1997). Enhancing sensitivity to facial expression of pain. Pain, 71(3), 279-284.

Stanik-Hutt, J. A., Soeken, K. L., Belcher, A. E., Fontaine, D. K., \& Gift, A. G. (2001). Pain experiences of traumatically injured patients in a critical care setting. American Journal Of Critical Care: An Official Publication, American Association Of Critical-Care Nurses, 10(4), 252-259.

Stein-Parbury, J., \& McKinley, S. (2000). Patients' experiences of being in an intensive care unit: a select literature review. American journai Of Criticai Care: An Official Publication, American Association Of Critical-Care Nurses, 9(1), 20-27.

Stuppy, D. J. (1998). The Faces Pain Scale: reliability and validity with mature adults. Applied Nursing Research: ANR, 11(2), 8489. 
Taylor, L. J., \& Herr, K. (2002). Assessment. Evaluation of the Faces Pain Scaie with minority oider adults. Journal of Gerontological Nursing, [28](4), 15-23.

Thomas, L. A. (2003). Clinical management of stressors perceived by patients on mechanical ventilation. AACN Clinical Issues: Advanced Practice in Acute \& Critical Care, 14(1), 73-81.

Walder, B., \& Tramer, M. R. (2004). Analgesia and sedation in critically ill patients. Swiss Medical Weekly: Official Journal Of The Swiss Society Of Infectious Diseases, The Swiss Society Of Internal Medicine, The Swiss Society Of Pneumology, 134(23-24), 333-346.

Webb, M. R., \& Kennedy, M. G. (1994). Behavioral responses and selfreported pain in postoperative patients. Journal Of Post Anesthesia Nursing, 9(2), 91-95.

Wilson, B., \& McSherry, W. (2006). A study of nurses inferences of patients physical pain. [Articie]. Journal of Clinical Nursing, 15, 459-468.

Young, J., Siffleet, J., Nikoletti, S., \& Shaw, T. (2006). Use of a Behavioural Pain Scale to assess pain in ventilated, unconscious and/or sedated patients. Intensive \& Critical Care Nursing: The Offlcial Journal Of The British Association Of Critical Care Nurses, 22(1), 32-39. 


\section{APPENDICES}




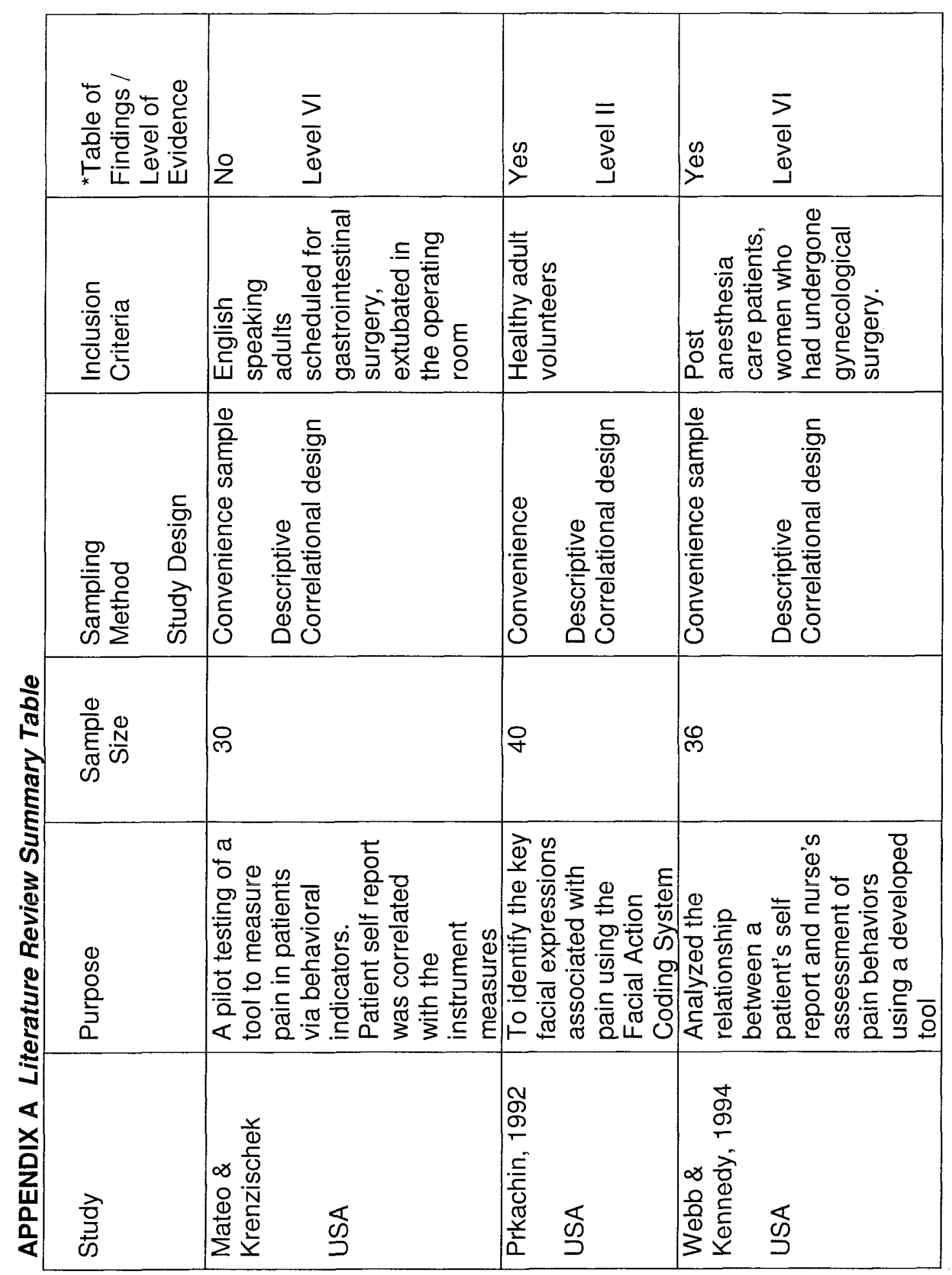




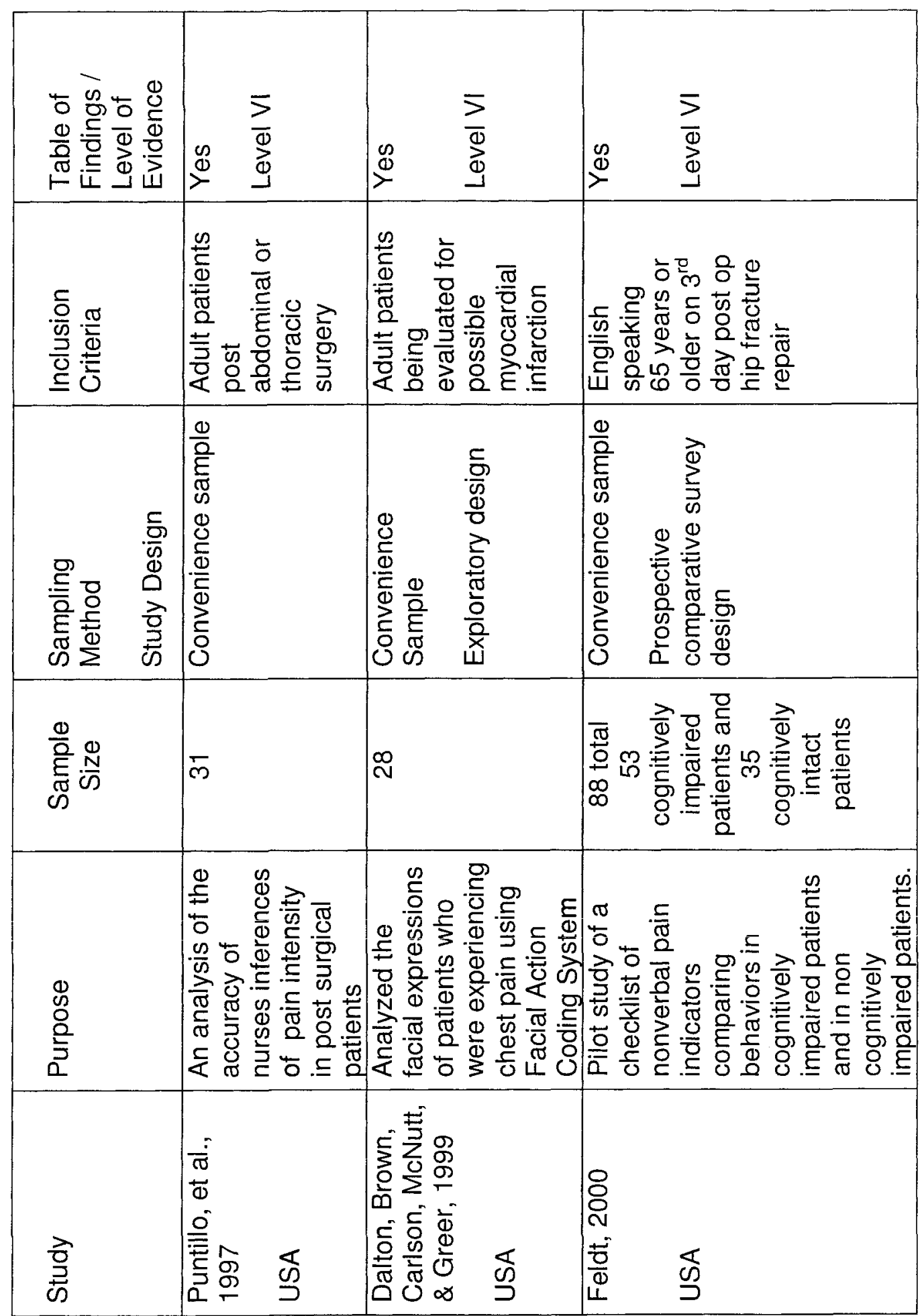




\begin{tabular}{|c|c|c|c|}
\hline 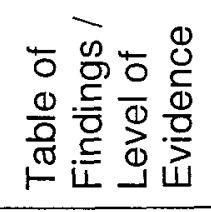 & 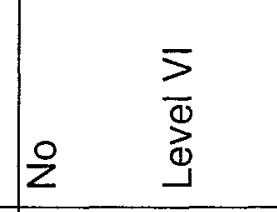 & 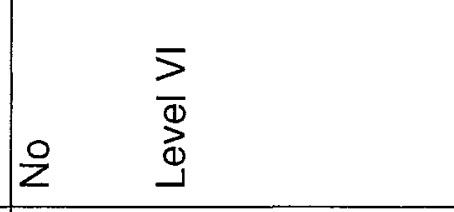 & 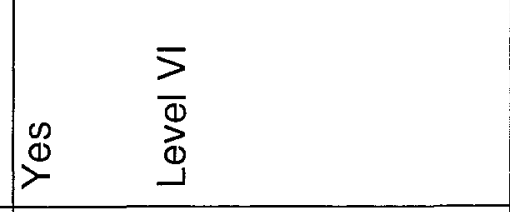 \\
\hline 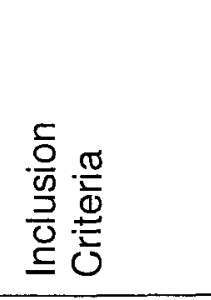 & 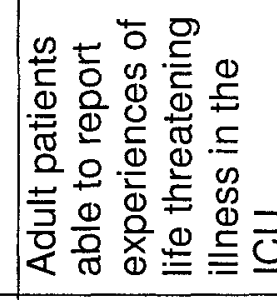 & 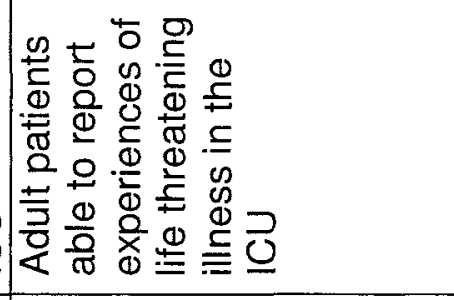 & 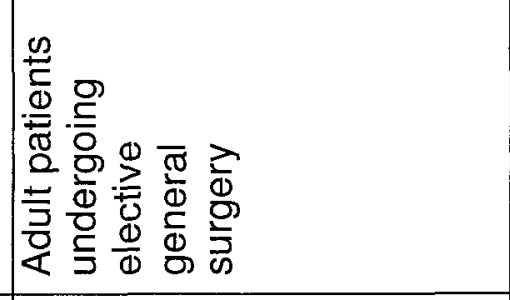 \\
\hline 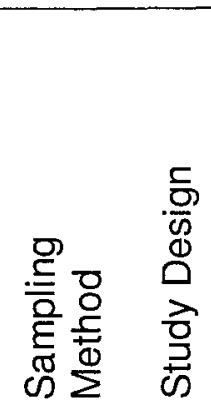 & 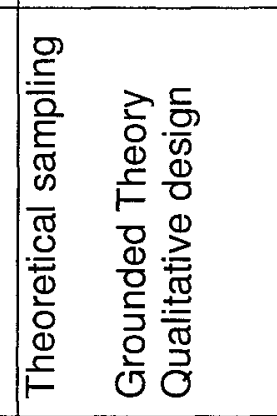 & 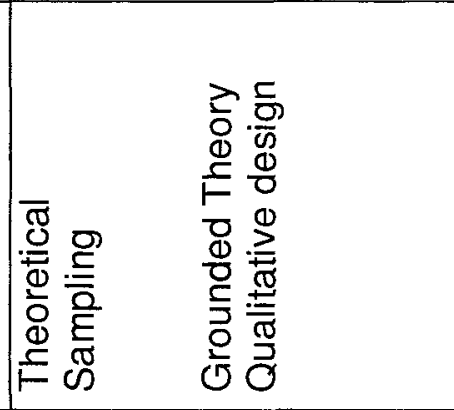 & 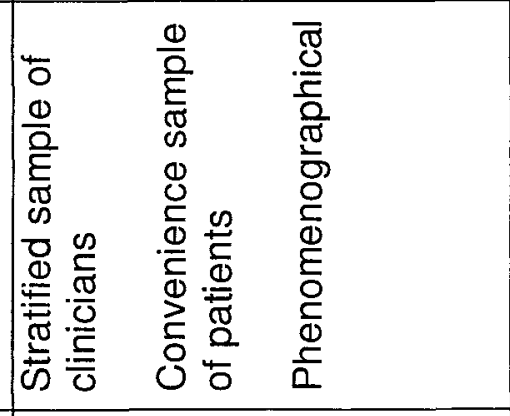 \\
\hline 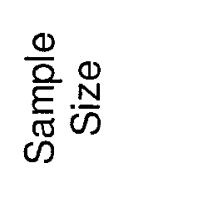 & $\infty$ & 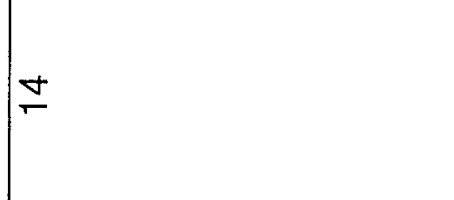 & 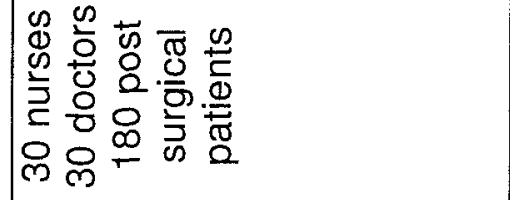 \\
\hline $\begin{array}{l}0 \\
0 \\
0 \\
\vdots \\
0 \\
0\end{array}$ & 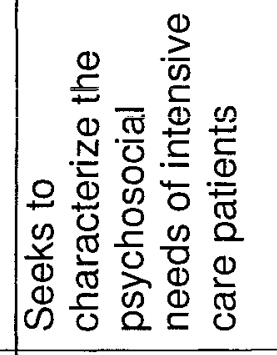 & 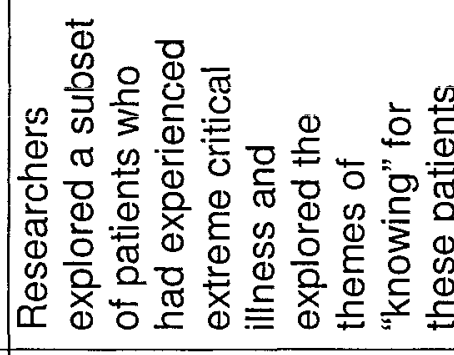 & 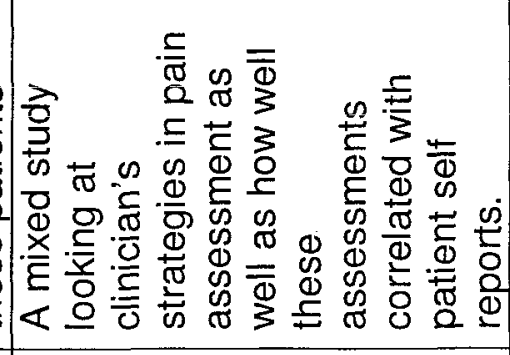 \\
\hline 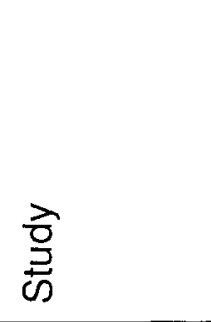 & 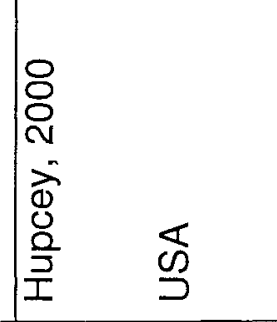 & 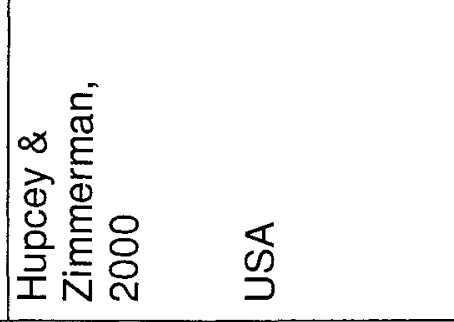 & 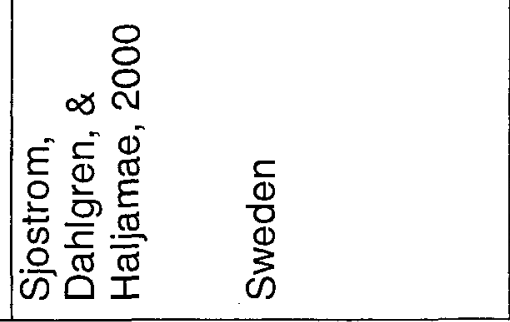 \\
\hline
\end{tabular}




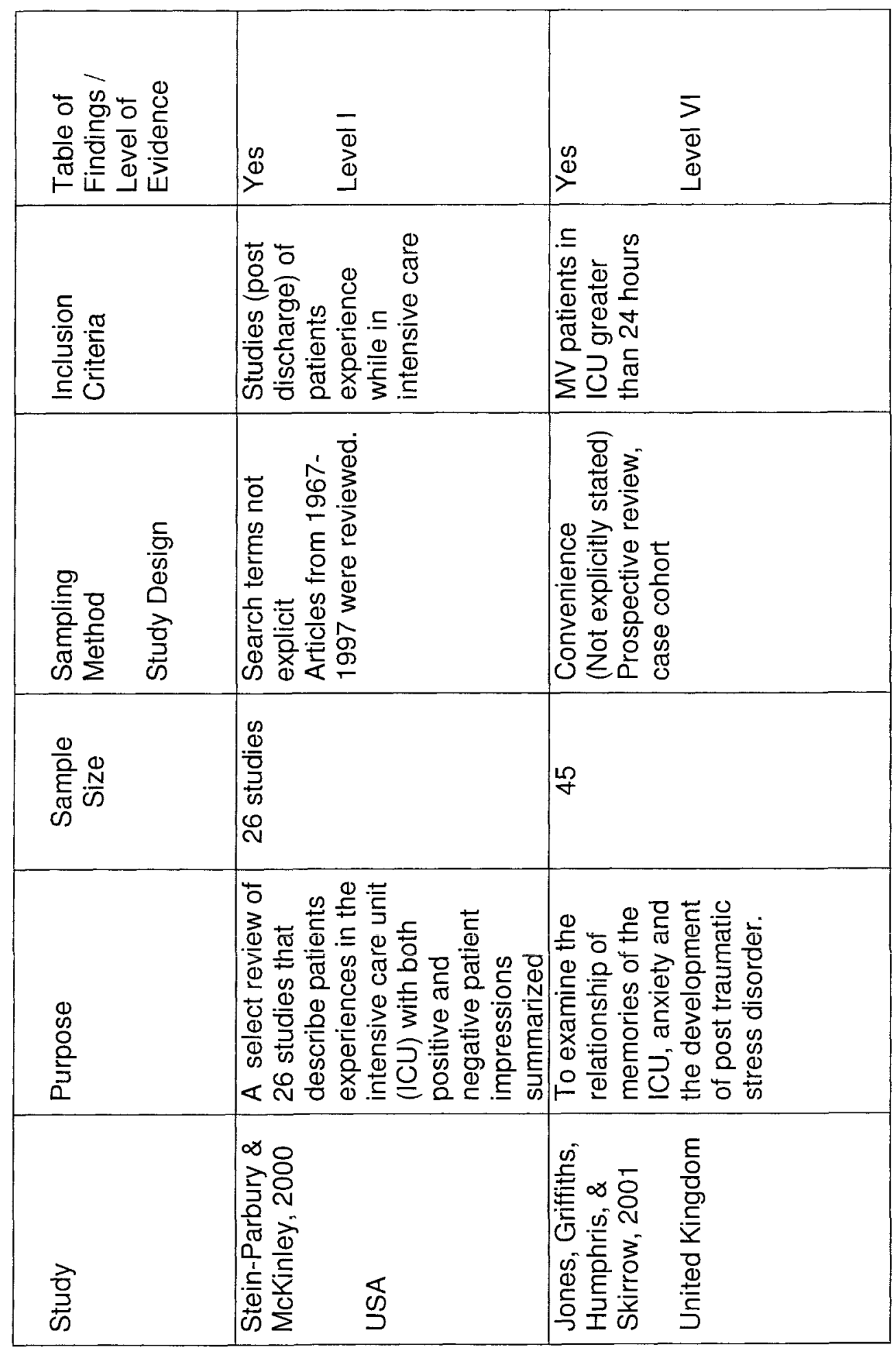




\begin{tabular}{|c|c|c|c|c|c|c|c|}
\hline \multicolumn{2}{|c|}{ 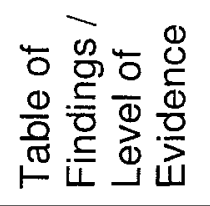 } & \multicolumn{2}{|r|}{$\overline{\bar{\Phi}}$} & \multicolumn{2}{|c|}{ 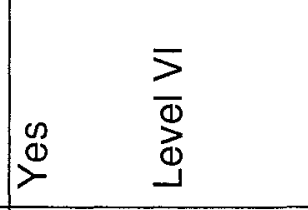 } & \multicolumn{2}{|c|}{ 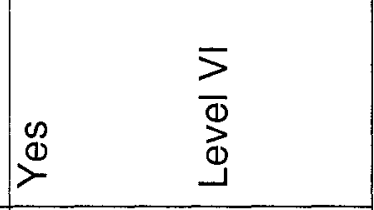 } \\
\hline \multicolumn{2}{|l|}{ 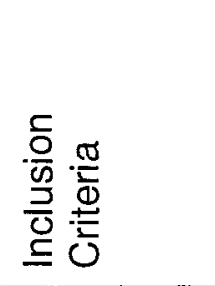 } & \multicolumn{2}{|l|}{$\begin{array}{l}\frac{0}{d} \\
\frac{0}{\pi} \\
\frac{\pi}{0} \\
0 \\
0 \\
2 \\
2\end{array}$} & \multicolumn{2}{|c|}{ 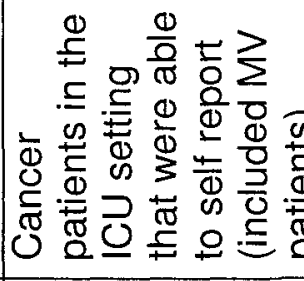 } & \multicolumn{2}{|c|}{ 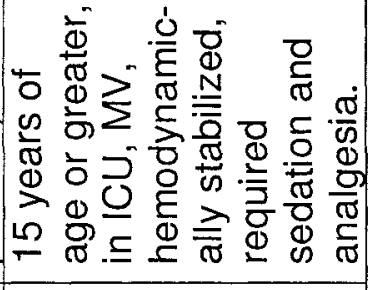 } \\
\hline 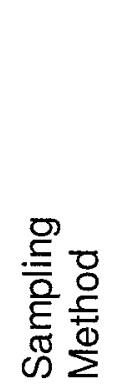 & 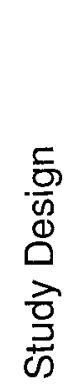 & 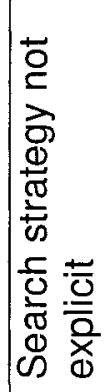 & & 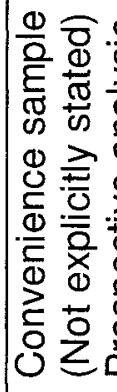 & & 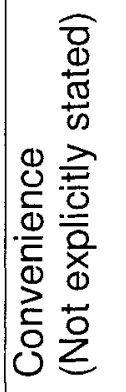 & $\begin{array}{l}\frac{0}{\overline{2}} \\
\frac{0}{0} \\
\frac{0}{0} \\
\frac{0}{0} \\
0\end{array}$ \\
\hline 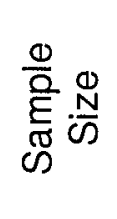 & & 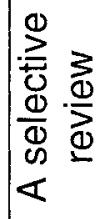 & & 음 & & প্ল & \\
\hline 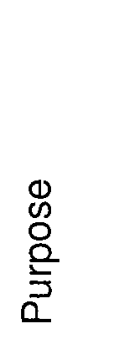 & & 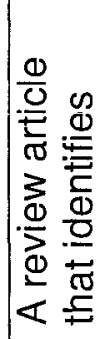 & 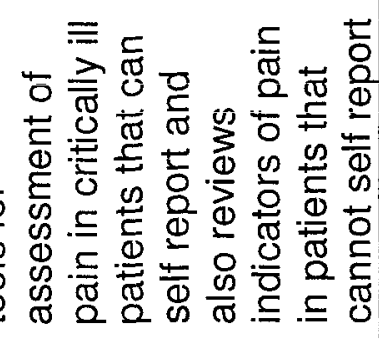 & 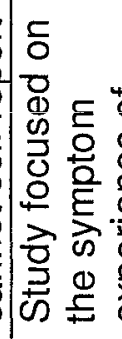 & 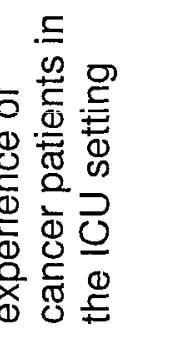 & 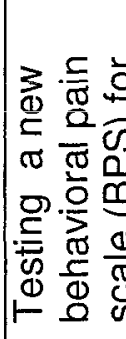 & 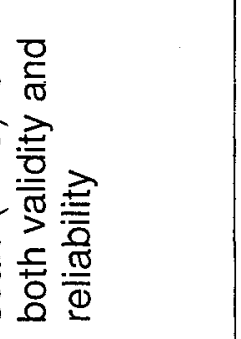 \\
\hline 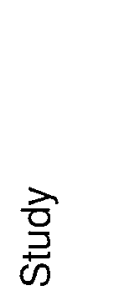 & & 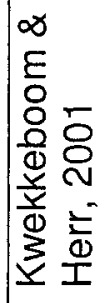 & ฏ & 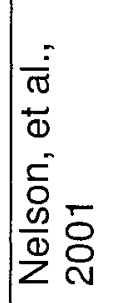 & 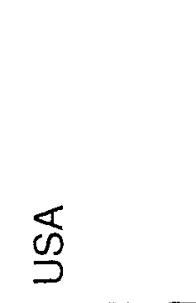 & 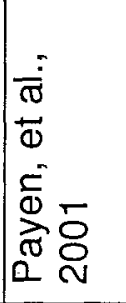 & 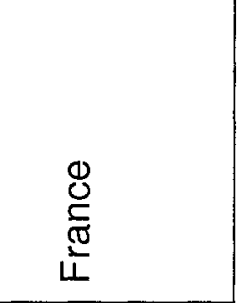 \\
\hline
\end{tabular}




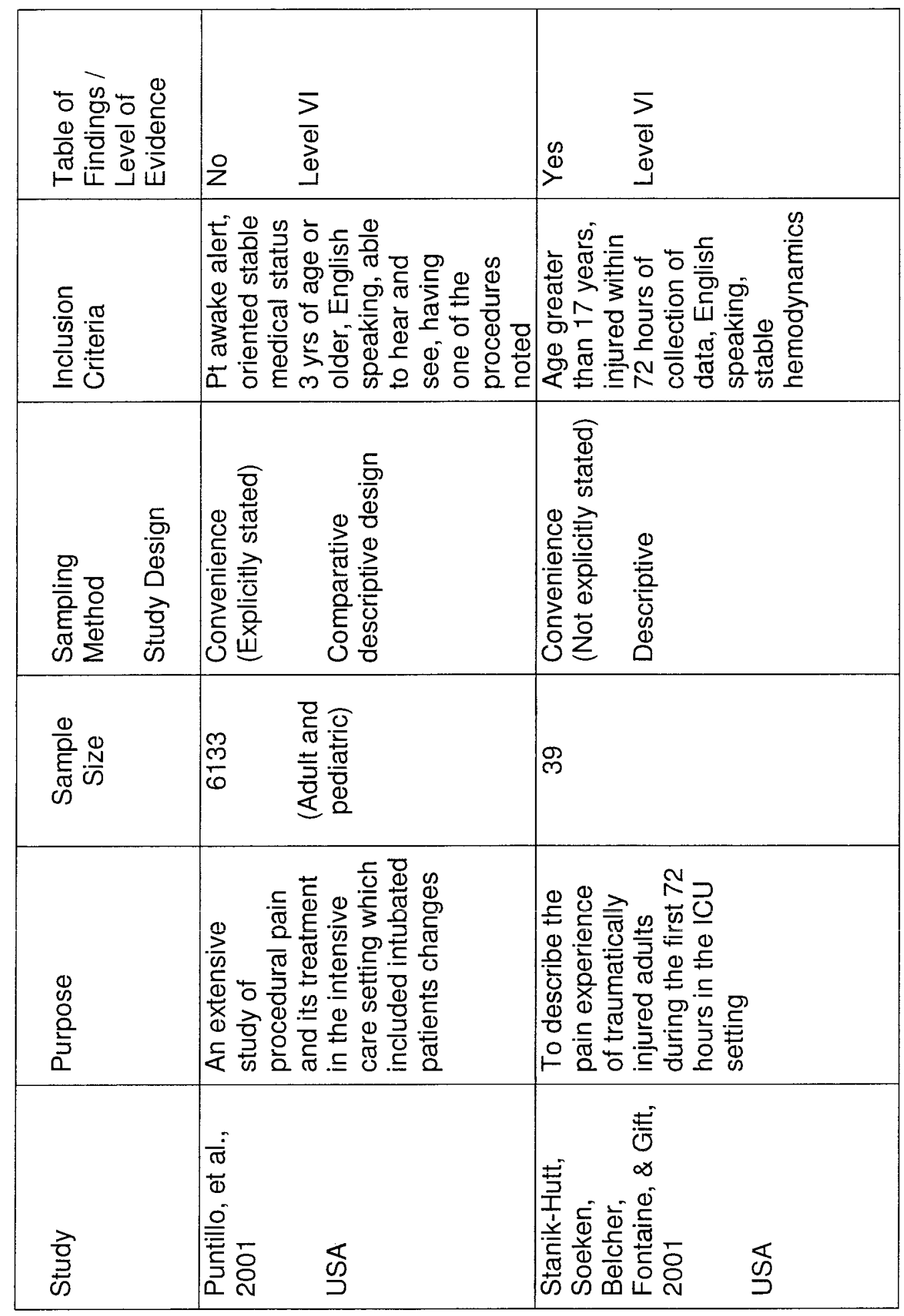




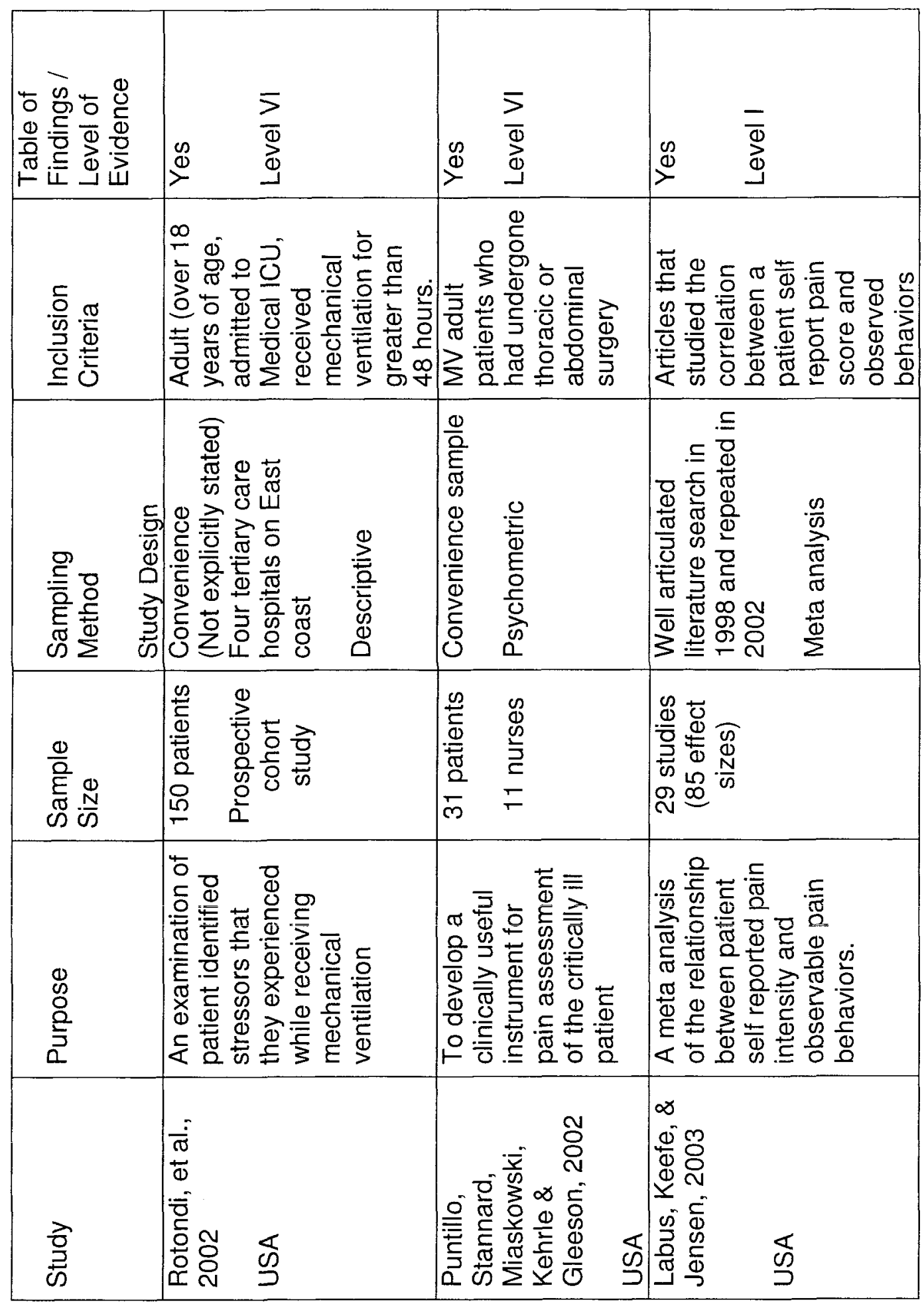




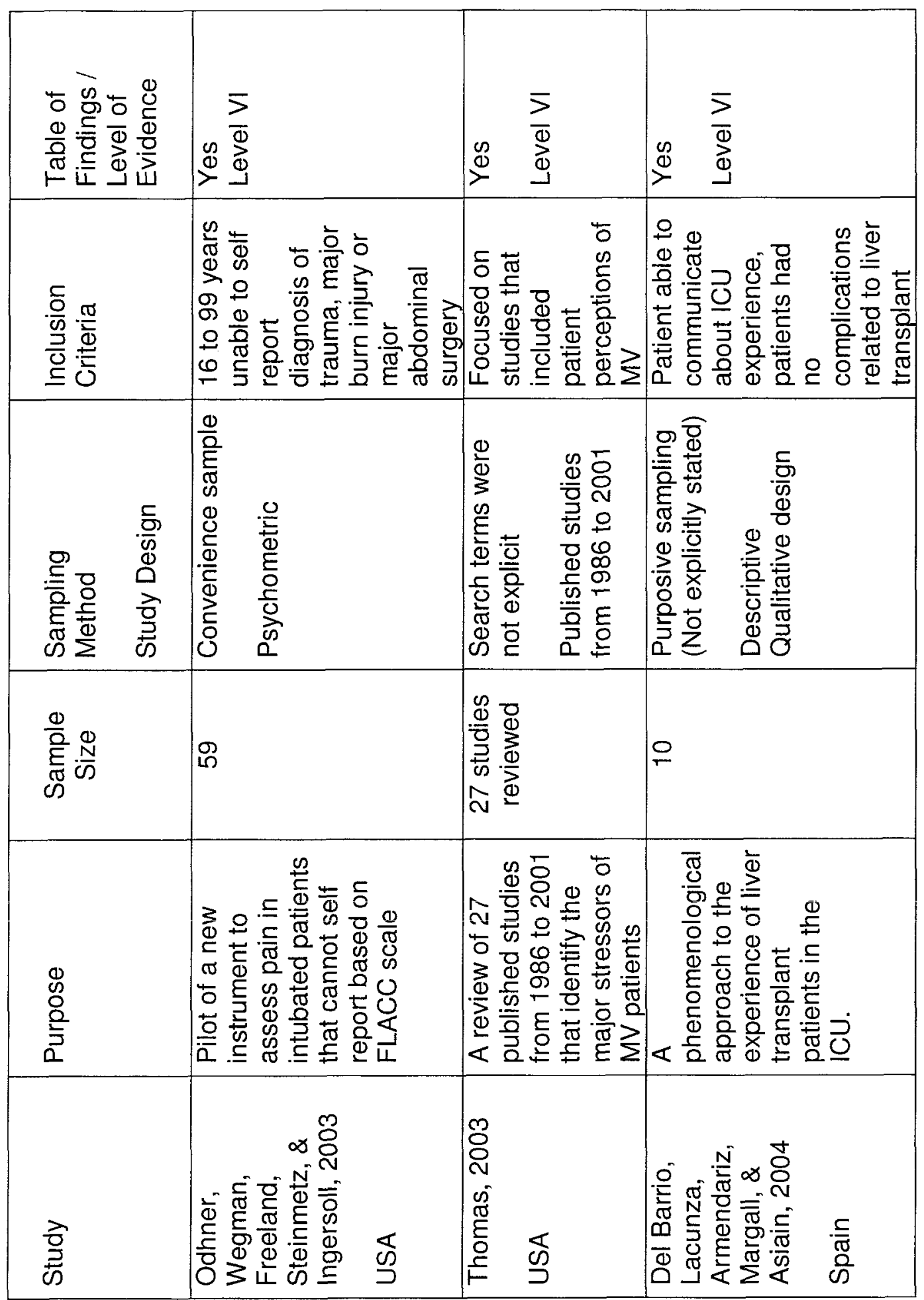




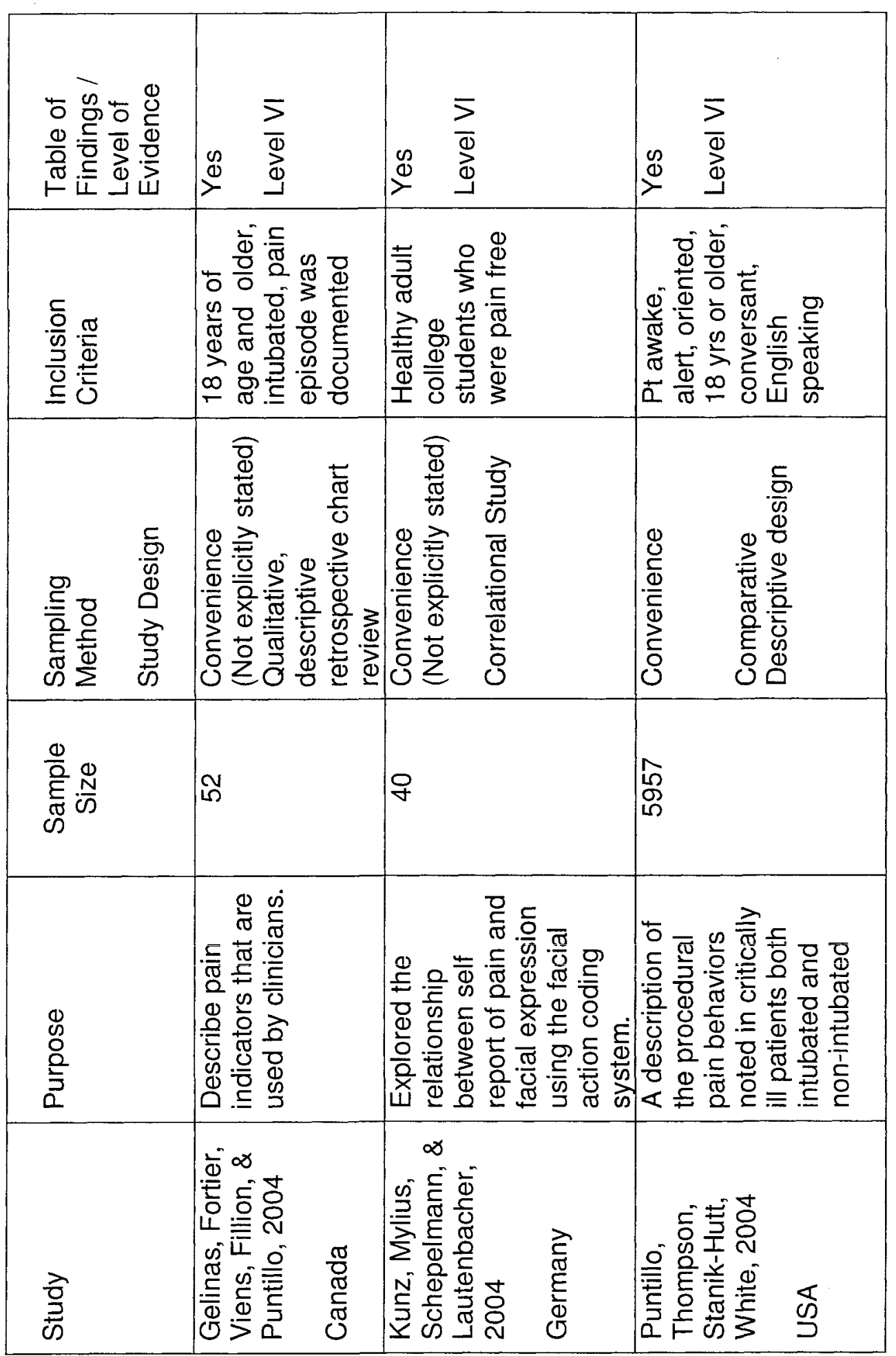




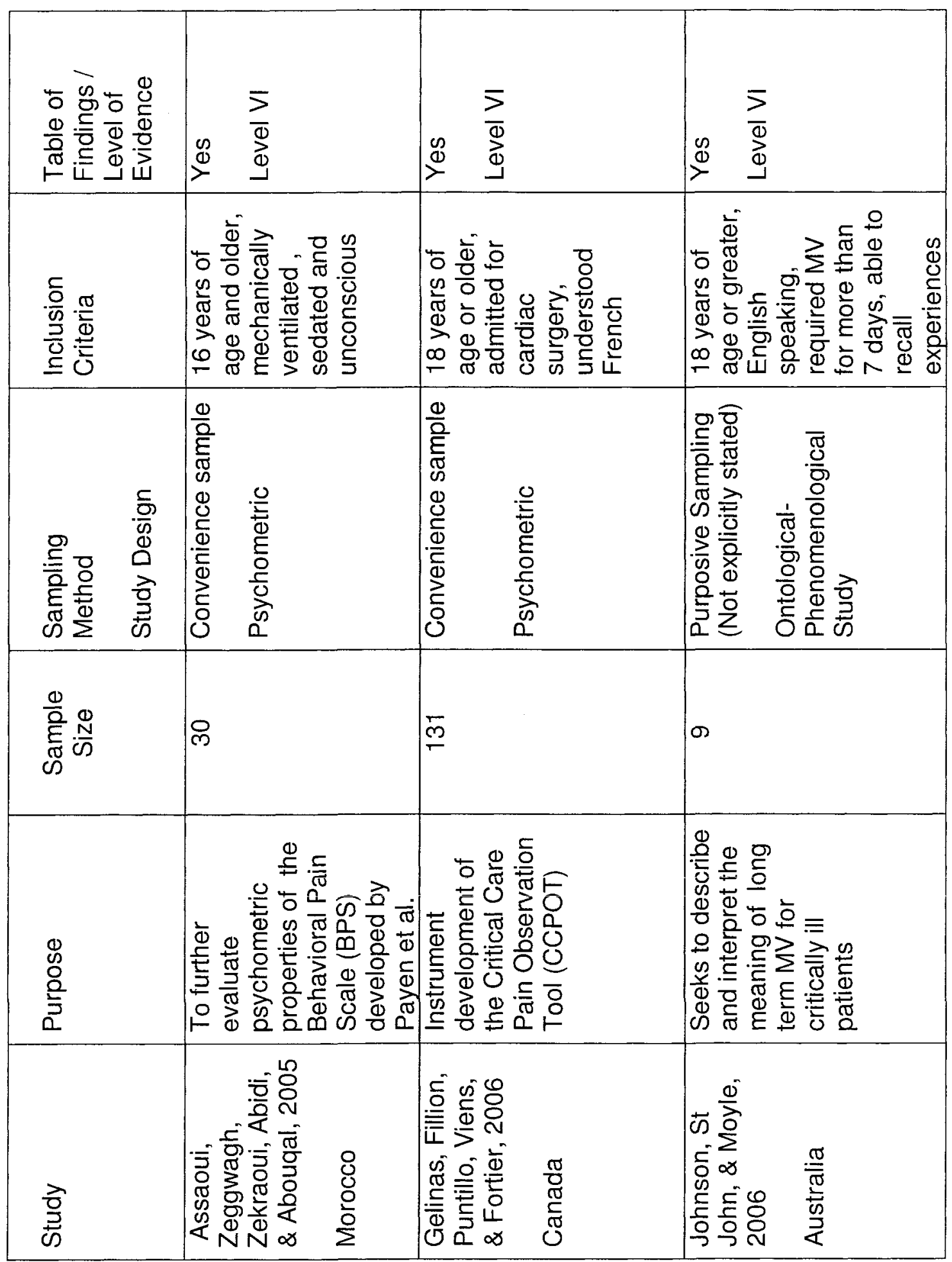




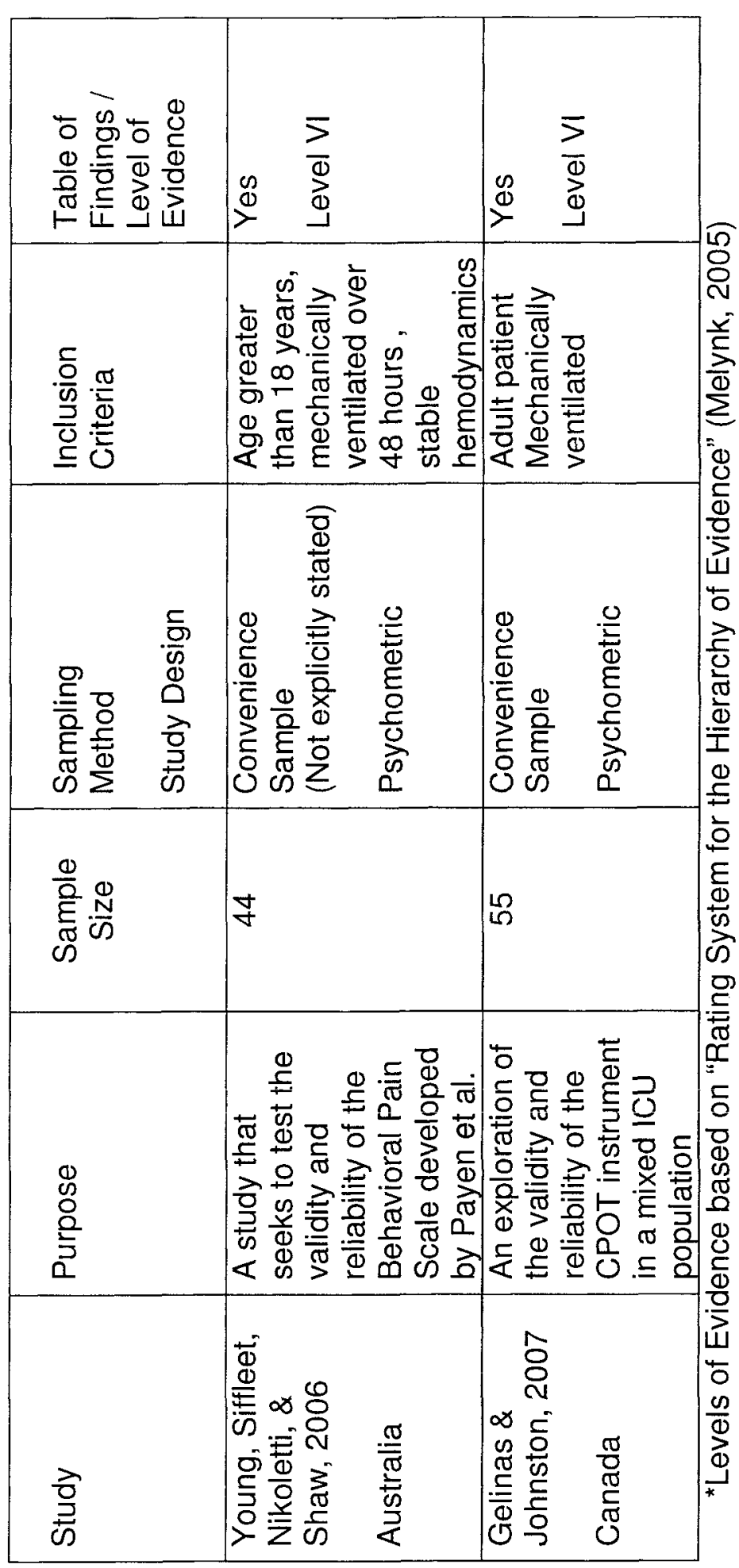

61 


\begin{tabular}{|c|c|c|c|c|}
\hline & 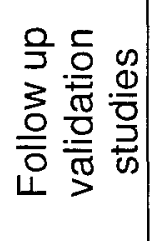 & 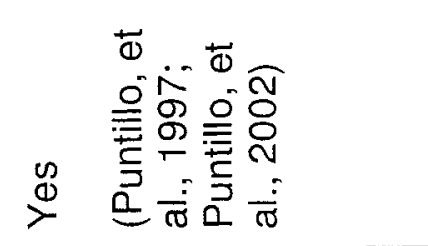 & 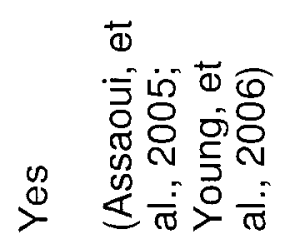 & \\
\hline & 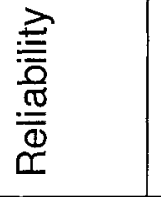 & 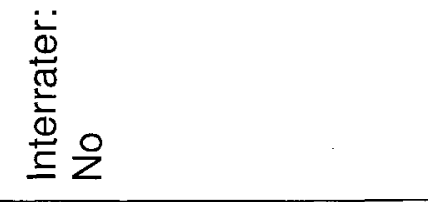 & 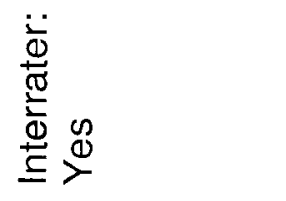 & \\
\hline & 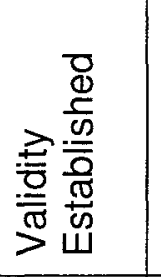 & 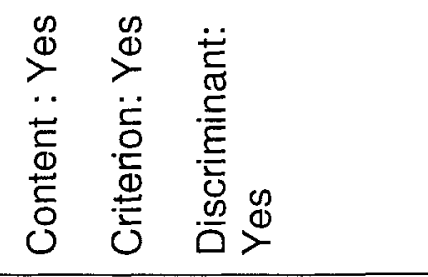 & 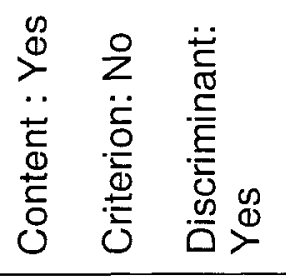 & \\
\hline & 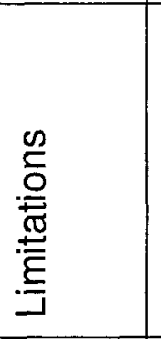 & 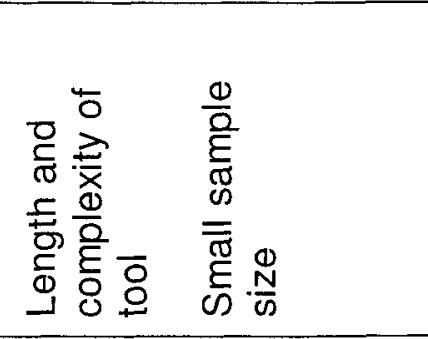 & 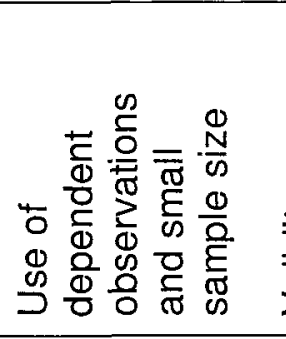 & 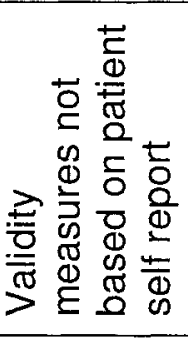 \\
\hline & 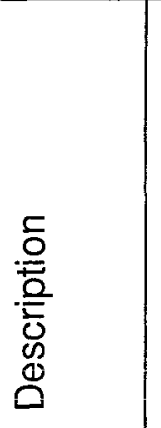 & 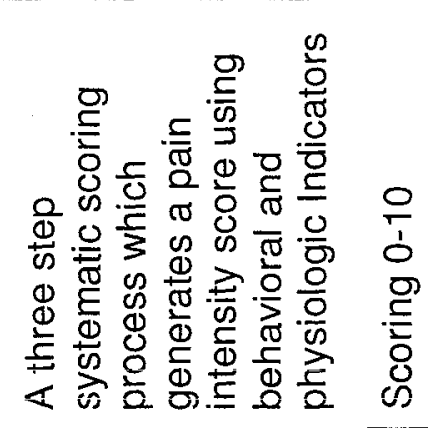 & 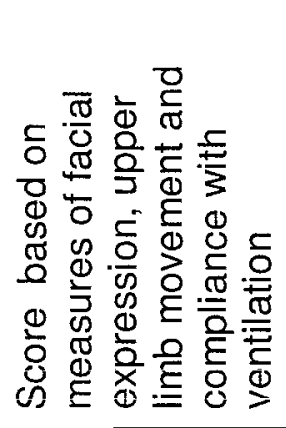 & 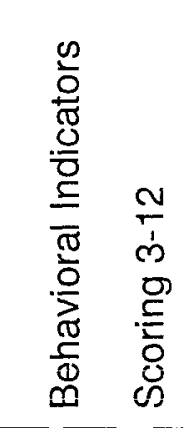 \\
\hline & 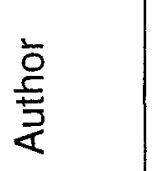 & 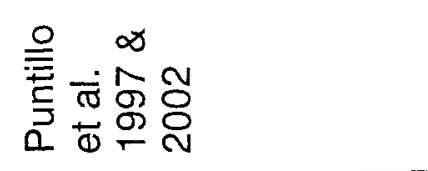 & 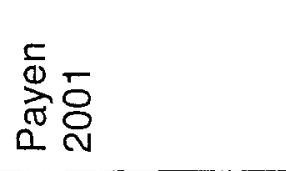 & \\
\hline & 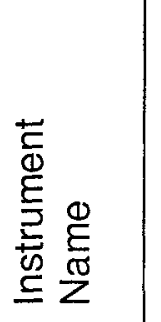 & 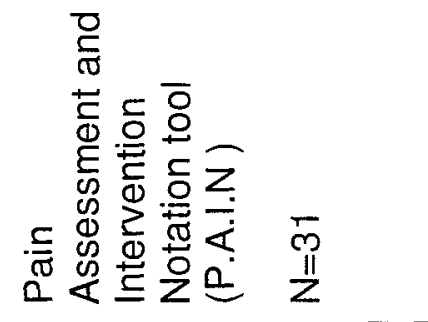 & 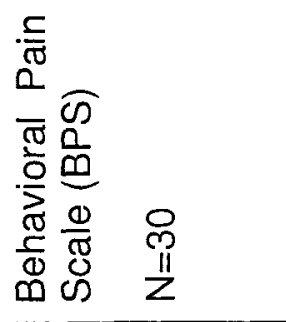 & \\
\hline
\end{tabular}




\begin{tabular}{|c|c|c|}
\hline 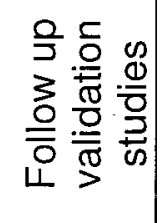 & ㄴ & \\
\hline 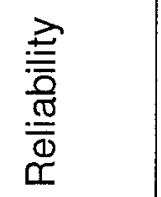 & 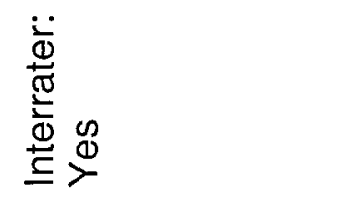 & \\
\hline 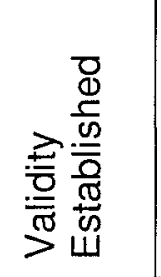 & 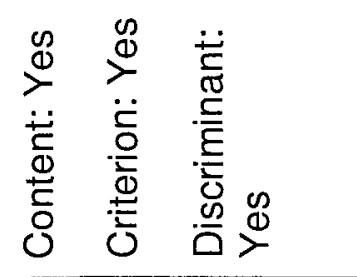 & \\
\hline 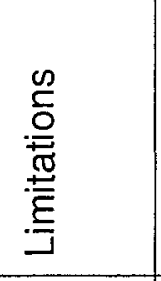 & 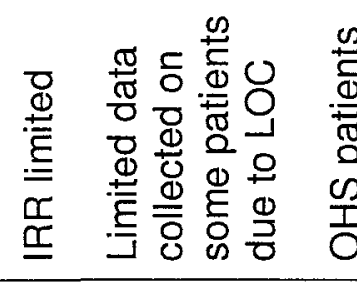 & \\
\hline 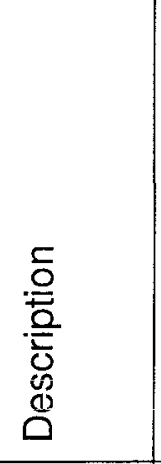 & 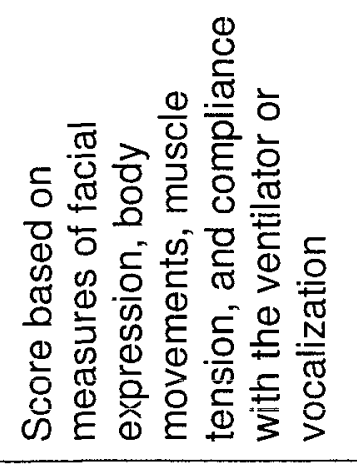 & 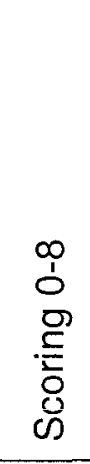 \\
\hline 高 & 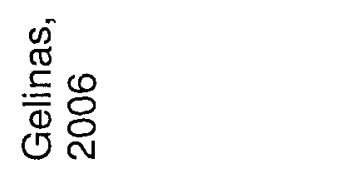 & \\
\hline 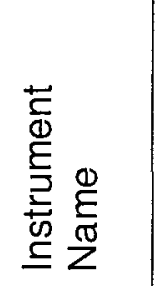 & 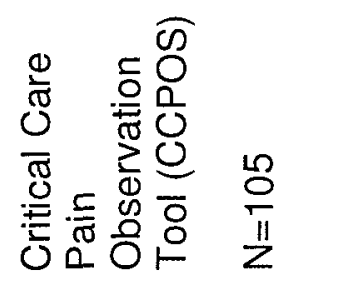 & \\
\hline
\end{tabular}




\section{University of New Hampshire}

Research Conduct and Compliance Services, Office of Sponsored Research Service Building, 51 College Road, Durham, NH 03824-3585

Fax: 603-862-3564

\section{2-Jul-2008}

Keane, Kathleen

Nursing, Hewitt Hall

13 Summer Street

Portland, ME 04102

IRB \#: 4346

Study: Validity and Reliability of the Critical Care Pain Observation Tool: A Pilot (Replication) Study

Approval Date: 16-Jul-2008

The Institutional Review Board for the Protection of Human Subjects in Research (IRB) has reviewed and approved the protocol for your study as Expedited as described in Title 45, Code of Federal Regulations (CFR), Part 46, Subsection 110.

Approval is granted to conduct your study as described in your protocol for one year from the approval date above. At the end of the approval period, you will be asked to submit a report with regard to the involvement of human subjects in this study. If your study is still active, you may request an extension of IRB approval.

Researchers who conduct studies involving human subjects have responsibilities as outlined in the attached document, Responsibilities of Directors of Research Studies Involving Human Subjects. (This document is also available at http://www.unh.edu/osr/compliance/irb.html.) Please read this document carefully before commencing your work involving human subjects.

If you have questions or concerns about your study or this approval, please feel free to contact me at 603-862-2003 or Julie.simpson@unh.edu. Please refer to the IRB \# above in all correspondence related to this study. The IRB wishes you success with your research.

For the IRB,

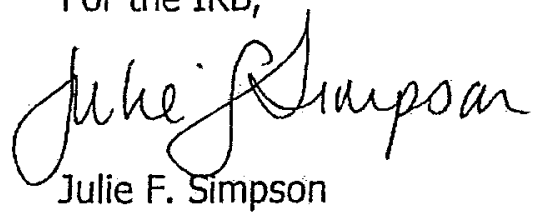

Julie F. Simpson

Manager

cc: File

Harkless, Gene 


\section{Maine Medical Center RESEARCH INSTITUTE}

OFFICE OF RESEARCH ADMINISTRATION

\begin{tabular}{|c|c|}
\hline To: & $\begin{array}{l}\text { Kathleen Keane, RN, BSN } \\
\text { Maine Medical Center } \\
\text { Cardiac Surgery Recovery Unit } \\
22 \text { Bramhall Street } \\
\text { Portland, ME } 04102\end{array}$ \\
\hline & Notice of Expedited Approval \\
\hline
\end{tabular}

(IRB \#3366) Validity and Reliability of the Critical Care Pain Observation Tool (CPOT): A Pilot [Replication] Study

Date: $\quad 6 / 27 / 2008$

This is to inform you that on 6/27/2008 Maine Medical Center IRB has approved the above research study, including:

- Informed Consent Dacument, June 23, 2008

- Invitation to participate in a research study at Maine Medical Center

- Screening tools and scale used in the CCPOT replication study

- CAM ICU worksheet

This study has received Expedited Approval according to federal regulation 45 CFR $46.110(\mathrm{~b})(1)$. The purpose of this study is to measure the discriminant (discriminant function analysis is used to determine which variables discriminate between two or more naturally occurring groups) and criterion validity as well as the reliability of the CPOT tool.

Please be aware that this action will be brought before the full board for its sanction at the meeting on $07 / 29 / 2008$.

The approval period is from 6/27/2008 to 6/27/2009. Your study number is 3366. Please be sure to reference this number in any correspondence with the IRB.

Please be aware that even though you now have IRB approval, it is Maine Medical Center's policy that al\} commercially funded protocols, or protocols subject to sub-contract, must have a fully executed contract (signed by all parties) prior to beginning any activity related to this protocol.

Before a patient can be entered into this project, heishe must sign and be given a copy of the informed consent document. The original consent form should be kept in your files, available for review for up to three years from the date of termination of the project. A copy should be kept in the patient's chart.

Continued approval is conditional upon your compliance with the following requirements:

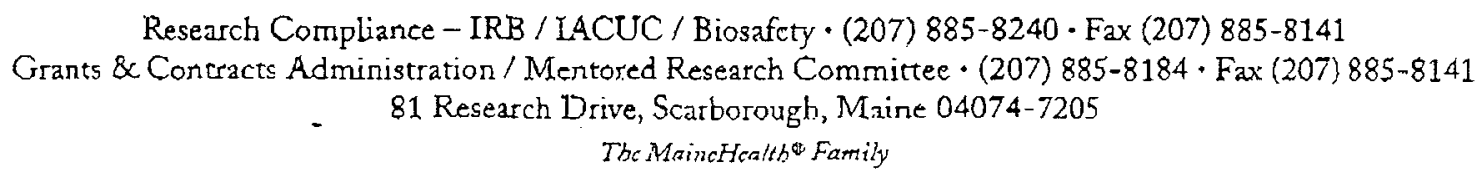


- All protocol amendments and changes to approved research must be submitted to the IRB and not be implemented until approved by the IRB except where necessary to eliminate apparent immediate hazards to the study subjects.

- Significant changes to the study site and significant deviations from the research protocol must be reported.

- Serious and unexpected adverse events must be promptly reported to the IRB

- Please complete and submit reports to the IRB as follows:

Renewal of the study - complete and return the Progress Report Request 4-6 weeks prior to the expiration of the approval period. The study cannot continue after $6 / 27 / 2009$ until re-approved by the IRB.

Completion, termination, or if not renewing the project - send the report upon completion of the study.

We (I) certify that the Maine Medical Center Institutional Review Board is in compliance with good clinical practice, as defined by the U.S. Food and Drug Administration guidelines, and the International Conference of Harmonization guidelines.

Please call our office if you have any questions about the terms of this approval (Research Compliance Office, 207-885-8195).

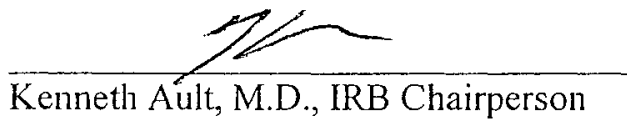

Enclosure: Informed Consent Document

Copy: File 
- All protocol amendments and changes to approved research must be submitted to the IRB and not be implemented until approved by the IRB except where necessary to eliminate apparent immediate hazards to the study subjects.

- Significant changes to the study site and significant deviations from the research protocol must be reported.

- Serious and unexpected adverse events must be promptly reported to the IRB

- Please complete and submit reports to the IRB as follow's:

Renewal of the study - complete and retum the Progress Report Request 4-6 weeks prior to the expiration of the approval period. The study cannot continue after 6/27/2009 until re-approved by the IRB.

Completion, termination, or if not renewing the project - send the report upon completion of the study.

We (I) certify that the Maine Medical Center Institutional Review Board is in compliance witl good clinical practice, as defined by the U.S. Food and Drug Administration guidelines, and the International Conference of Harmonization guidelines.

Please call our office if you have any questions about the terms of this approval (Research Compliance Office, 207-885-8195).

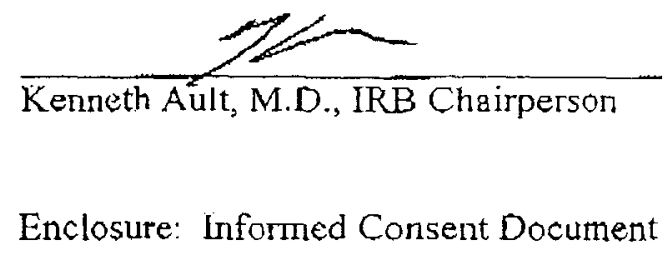

Copy: File 


\section{FUNDING ACKNOWLEDGEMENT}

The author gratefully acknowledges the funding support of the American Association of Critical Care Nurses (AACN) which awarded a 2008 AACN Clinical Inquiry Grant to this study. 